Elsevier

BBA 86106

\title{
THE PROTON CONDUCTING F-PART OF BACTERIAL ATP SYNTHASES
}

JÜRGEN HOPPE and WALTER SEBALD

GBF - Gesellschaft für Biotechnologische Forschung mbH, Mascheroder Weg I, D-3300 Braunschweig (F.R.G.)

(Received July 25th, 1983)

\section{Contents}

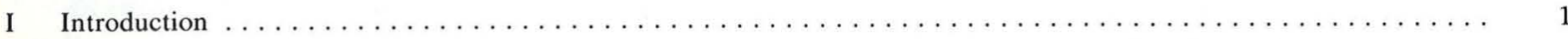

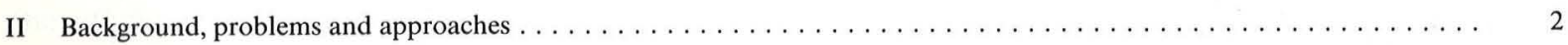

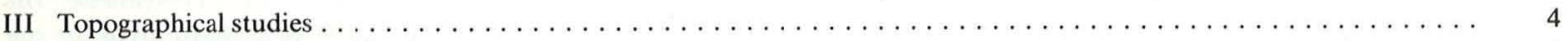

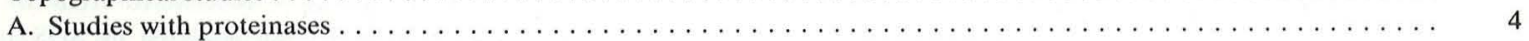

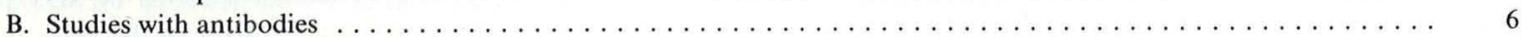

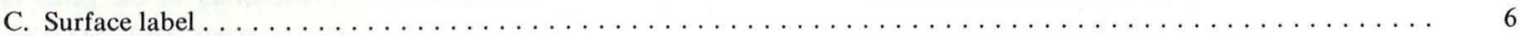

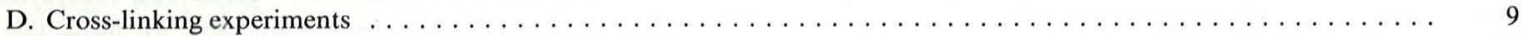

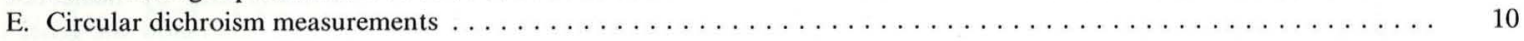

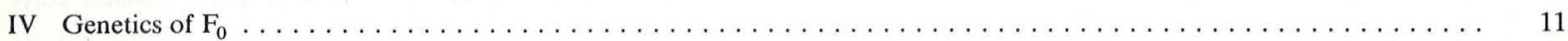

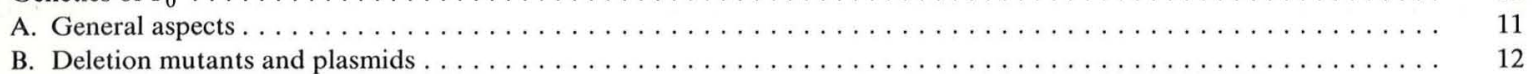

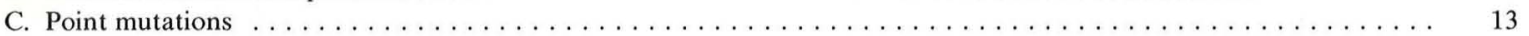

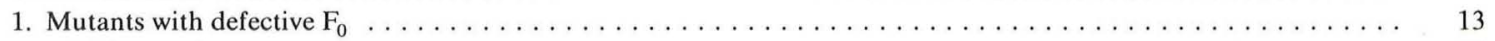

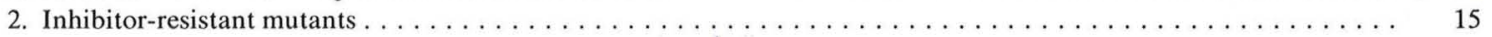

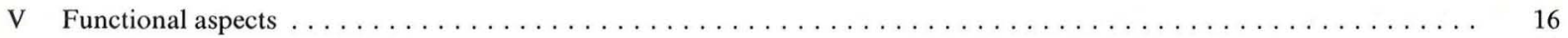

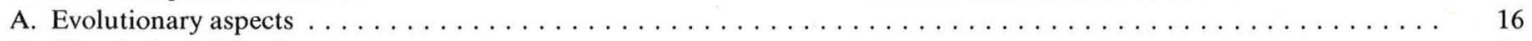

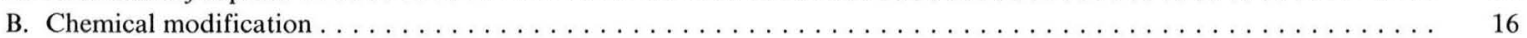

C. $\mathrm{H}^{+}$conduction of reconstituted subunits $\ldots \ldots \ldots \ldots \ldots$

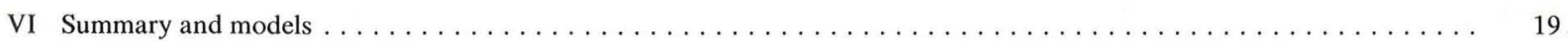

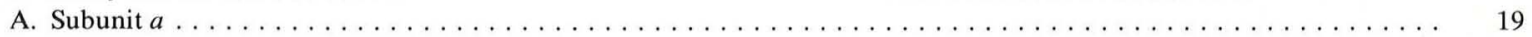

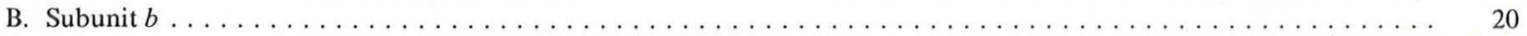

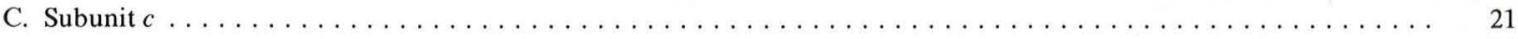

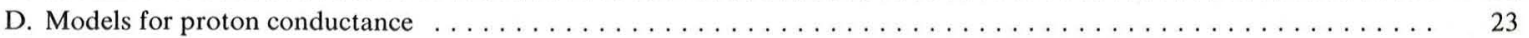

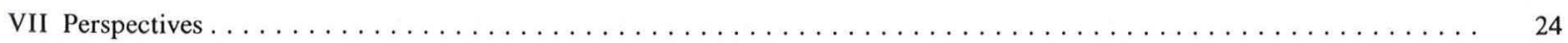

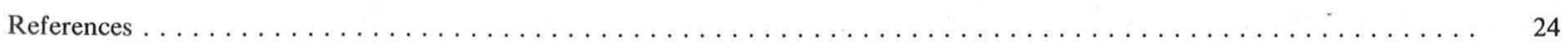

Abbreviations: DCCD, $N, N^{\prime}$-dicyclohexylcarbodiimide; PTH, phenylthiohydantoin; TID, 3-trifluormethyl-m-(iodophenyl)diazirine; NCCD, N-(2,2,6,6-tetramethylpiperidyl-1-oxyl)$N^{\prime}$ (cyclohexyl)carbodiimide.

\section{Introduction}

The membrane-integrated part $\mathrm{F}_{0}$ of the ATP synthase translocates protons across the mem- 
brane. In the whole ATP synthase $\left(F_{1} F_{0}\right)$ the $F_{0^{-}}$ mediated proton transport is tightly coupled to the synthesis or hydrolysis of ATP catalysed by the $F_{1}$-ATPase part. By the removal of $F_{1}$, the proton pathway in $F_{0}$ is opened, and can be studied pathway in $F_{0}$ is opened, and can be studied
independently. $F_{0}$ represents, therefore, an interestindependently. $F_{0}$ represents, therefore, an interesting and up to now unique system for analysis of (i) the structure and function of a proton conductor, and (ii) the coupling of the $\mathrm{F}_{0}$-mediated proton transport to the hydrolysis or synthesis of ATP occurring in the $\mathrm{F}_{1}$-ATPase.

Several recent reviews covered the genetics of the ATP synthase [1,2], the nucleotide sequence of the ATP synthase genes of $E$. coli (Walker, J.E., Saraste, M. and Gay, N.J., unpublished results), the proton-ATPase from bacteria and mitochondria [4], the structural basis of proton-translocating protein function [5], and the structure and genetics of the proteolipid subunit of the ATP This review tries to collect new proteinchemical data on $F_{0}$ and to combine them with genetical and functional data in order to give the present-day knowledge on the structure-function relationships in this proton conductor. Although detailed and definite information has been obtained on several structural and functional aspects of $F_{0}$, we are still far from an understanding of the proton transport at a molecular level.

\section{Background, problems, and approaches}

The ATP synthase occurs in remarkably similar form in procaryotic and eucaryotic cells. Accord-

TABLE I

ACTIVITIES OF $\mathrm{F}_{1} \mathrm{~F}_{0}$ FROM ESCHERICHIA COL

Values are taken from Ref. 74.

\begin{tabular}{|c|c|c|c|}
\hline \multirow[t]{2}{*}{ Fraction } & \multicolumn{2}{|c|}{ Electro-impelled $\mathrm{H}^{+}$conduction } & \multirow{2}{*}{$\begin{array}{l}\text { ATP-dependent } \\
\mathrm{H}^{+} \text {translocation } \\
\text { Fluorescence test }\end{array}$} \\
\hline & 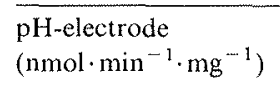 & $\begin{array}{l}\text { Fluorescence test } \\
\left(\mathrm{U}_{\mathrm{F} 1} \cdot \mathrm{mg}^{-1}\right)\end{array}$ & \\
\hline Membranes & - & - & 130 \\
\hline $\begin{array}{l}F_{1} \text {-depleted } \\
\text { membranes }\end{array}$ & 44 & 65 & - \\
\hline \multicolumn{4}{|l|}{ Liposomes with } \\
\hline $\mathrm{F}_{1} \mathrm{~F}_{0}$ & 5 & 16 & 2330 \\
\hline$F_{0}+F_{1}$ & 41 & 151 & 1910 \\
\hline & 870 & 2565 & 1 \\
\hline$F_{0}+D C C D$ & 2 & 24 & - \\
\hline
\end{tabular}

\section{Subunits}

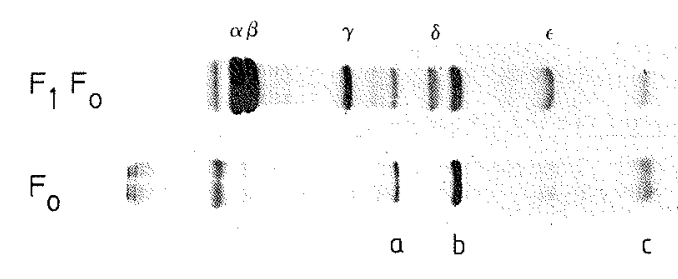

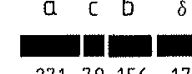
ATP synthase $F_{1} F_{0}$ and the $F_{0}$ were isolated from $E$. coll acrylamide gel electrophoresis. The order of the genes in the unc operon and the correlation of genes with ATP-synthase subunits was established genetically and by nucleotide sequence analysis $[1,12-23]$. The numbers below the genes indicate the number of amino acid residues in the subunit polypeptide.

ngly, our present knowledge on the proton-conducting $F_{0}$ part is derived from studies of the bacterial, mitochondrial or chloroplast protein each offering special experimental possibilities. In
Genes (atp operon)

Fig. 1. Subunits and genes of the E. coli ATP-synthase. The recent time, research has focused on the $F_{0}$ from Escherichia coli. The ATP synthase of this organism can now be prepared in large quantities with a can purity of at leas [7] and Fiedlet al. [8]. From these and Finlingame [7] and Fried er al. [8]. From these preparations the $\mathrm{F}_{0}$ part has been isolated by various procedures $[0-11]$. It contains three subunits $a, b$ and $c(\chi, \psi$ and $\omega$, or proteolipid or DCCD-binding protein) as shown in Fig. 1. The whole ATP synthase contains, in addition, the five $F_{1}$ subunits $\alpha, \beta, \gamma, \delta$ and $\epsilon$. These eight subunit polypeptides are coded for by the eight genes that polypeptides are coded for by the eight genes that form the atp (unc) operon (see section IV). The atp operon has bech well defined genetically, especially by Downie, et al. [1,12], and by Von Meyenburg and co-workers [13], and its nucleotide sequence has been determined [14-23]. Therefore the subunit composition of the ATP synthase and $\mathrm{F}_{0}$ from $E$. coli is proven. The amount of protein of $F_{0}$ subunits $a, b$ and $c$ corresponds to molar ratio of $1: 2: 10$ according to Foster and Fillingam 24], or $1: 2: 12$ according 10 Von Meyenturg and co-workers [25]. For the mitochondrial [26] an chloroplast [27] ATP synthase, six proteolipi (subunit $c$ ) molecules have been determined. These different stoichiometries are difficult to explain for the time being. It is quite clear, however, that subunit $c$ exists at least in six copies per $F_{0}$. The dimeric form of subunit $b$ is also indicated by cross-linking exp

$E$ coli can be reinserted into artificial membranes, and proton conductance can be measured in response to a valinomycin-induced potassium diffusion potential [9-11] (Table I). The proton conductance is inhibited strongly by DCCD and by added $F_{1}$. Reconstituted $F_{0}$ rebinds $F_{1}$, and thereby, ATP-dependent proton translocation is restored. The dape I together with corresponding data measured with $F_{0}$ in whole membranes. Accordingly, both proton conductance and functional rebinding of $F_{1}$ can be used to analyse $F_{0}$.

The nucleotide sequence of the genes of all three $\mathrm{F}_{0}$ subunits of $E$. coli was determined independently by three groups in $1981[15,17,21]$. Amino-terminal amino acid sequences of the isolated subunits $a, b$, and $c$ were established [17] in order to prove the start of the individual subunit

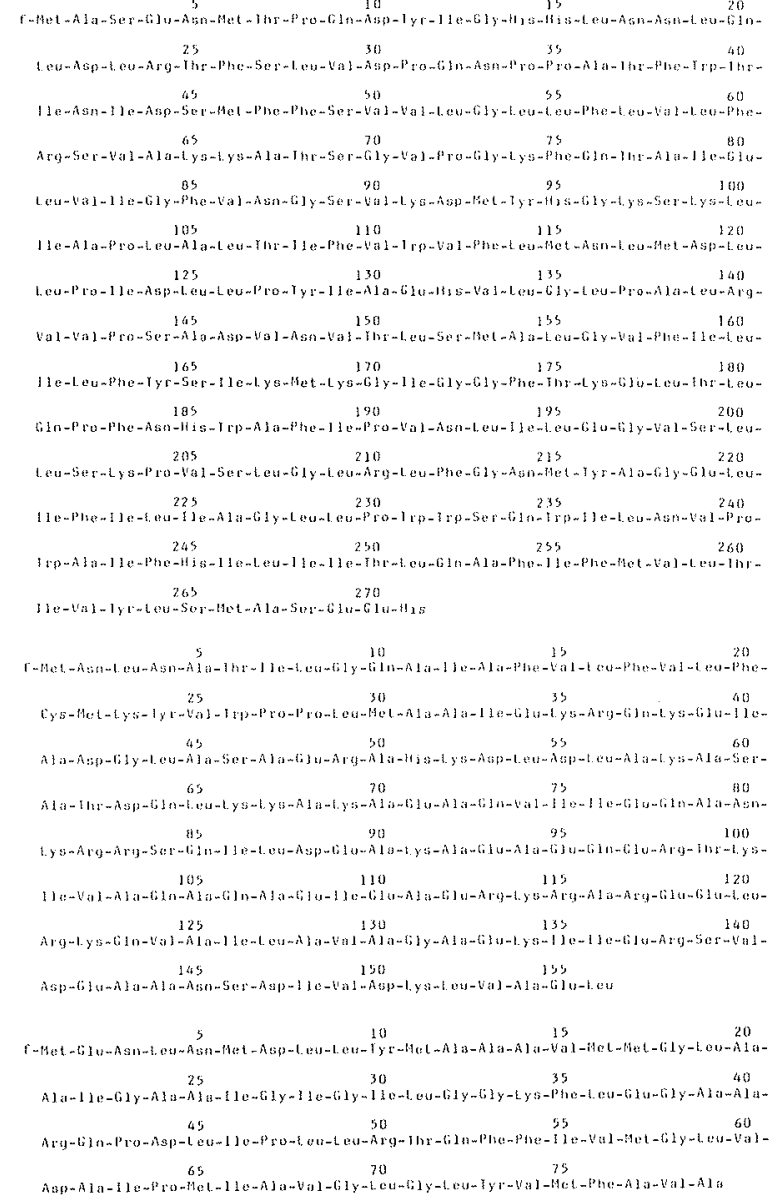

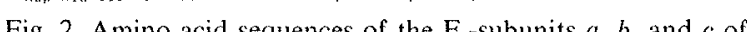
the ATP synthase from $E$. coli.

genes. The derived amino acid sequences of the three $F_{0}$ subunits are presented in Fig. 2. They have been extensively evaluated by means of computer programs with respect to secondary structure predictions, polarity profiles and homologies with corresponding subunits from other organisms $[3,4,28,29]$. A summary of such evaluation is also shown in Figs. 12, 13 and 15 in the last section of this review.

The established subunit composition and covalent structure of the $E$. coli $\mathrm{F}_{0}$ reflect a major achievement in the characterization of the ATP synthase proton channel. However, for the elucidation of $\mathrm{F}_{0}$-mediated proton conductance, additional information is needed (i) on the three-dimensional structure of the protein, and (ii) on the 
functional amino acid residues and domains constituting the proton pathway and participating in the coupling of $F_{0}$ and $F_{1}$ functions.

A high resolution of the three-dimensiona structure of $F_{0}$ will be achieved finally only by $\mathrm{X}$-ray analysis after crystallization of the protein. With other integral membrane proteins, two-dimensional crystals [30-34] and, more recently, also three-dimensional crystals [35-37] have been produced Crystals of the $F_{0}$ protein have not yet been duced. Crystals of the $\mathrm{F}_{0}$ protein have not yet been obtained. Anyway, $X$-ray anly of complex teins, as $F_{0}$, will be exceedingly complicated, an will probably always depend on auxiliary information from other structural studies.

As described in subsections IIIA-C, the surface of $F_{0}$ has been mapped by probes which have access either only from the polar water phase or antibodies are valuable tools, not only for identification of polar domains but also for the de termination of the orientation of the polypeptide chains in the membrane. The surface of $F_{0}$ access ble from the lipid bilayer has been studied with photoreactive membrane-permeating probes. Especially, carbene labels of broad specificity offer promising possibilities, since they shoul promisng possibilies, sine they should act like a razor blade and modify all acessible residues at the protein/lipid interphase. Not only would this allow an identification of membrane-embedde polypeptide segments, but, in addition, the patter of accessible residues might yield information on secondary structures of the polypeptide chain.

The study of subunit contacts in $F_{0}$ by cross-linking experiments is handicapped (i) by the low content of reactive side-chains and (ii) by the complex subunit composition. These difficulties could be overcome partially by using photoactivated bifunctional reagents for cross-linking and specific antibodies for the identification of cross-linked subunits.

Further information on the structure of $F_{0}$ may be derived from the analysis of $F_{0}$ mutants. Amino acid residues altered in DCCD- or oligomycin-resistant mutants might be involved in the binding of the inhibitors, and might therefore be located in proximity to each other at the surface of the molecule. Subunits from assembly-deficient mutants might be altered in residues involved in intermolecular or intramolecular protein contacts.
Several approaches were applied to identify the functional amino acid residues and domains in the $F_{0}$. Due to the ubiquitous occurrence of $F_{0}$, it is feasible to compare the amino acid sequences of $F_{0}$ subunits from very distantly related organisms. Based on the assumption that the mechanism of proton conductance remained unchanged during evolution, it can be expected that the group of invariant amino acids also comprises the functional residues.

Chemical modification may lead to the identification of functional residues, provided that the reaction of a defined residue can be correlated with an inhibition of $F_{0}$ functions.

Molecular genetics and genetic engineering offer further promising possibilities to study functional properties of $\mathrm{F}_{0}$. Especially in $E$. coli, but also in yeast, a variety of me of these strains, $F_{0}$ appears to be normally assembled, and, therefore, functional residues might have been modified by the mutation. The altered residues might be identified by protein or DNA sequence analysis Furthermore, the function of the different $F_{0}$ subunits has been studied by constructing strains where one or two of the $\mathrm{F}_{0}$ subunits are missing.

\section{III.Topographical studies}

\section{IIIA. Studies with proteinases}

The assymmetry of membrane proteins has been investigated in many instances by proteinase treatment of whole membranes and analysis of the and $\mathrm{N}$-terminal segments as well as the location of some internal polar loops have been determined, for example, in the bacteriorhodopsin, by treat ment of the purple membrane with papain, trypsin and chymotrypsin [42-44]. These studies, together with crystallographic data $[30,31]$ and the primary tructure $[43,45]$, provided information on the folding and orientation of this polypeptide in the membrane $[46,47]$

First experiments on proteinase treatment of isolated $\mathrm{F}_{0}$ from PS-3 were described by Sone et al. 48]. An $\mathrm{F}_{0}$ subunit of $M_{\mathrm{r}} 13000$ was readily digested with trypsin and nagarse, but the proton permeability of the $F_{0}$ was not affected by pro-

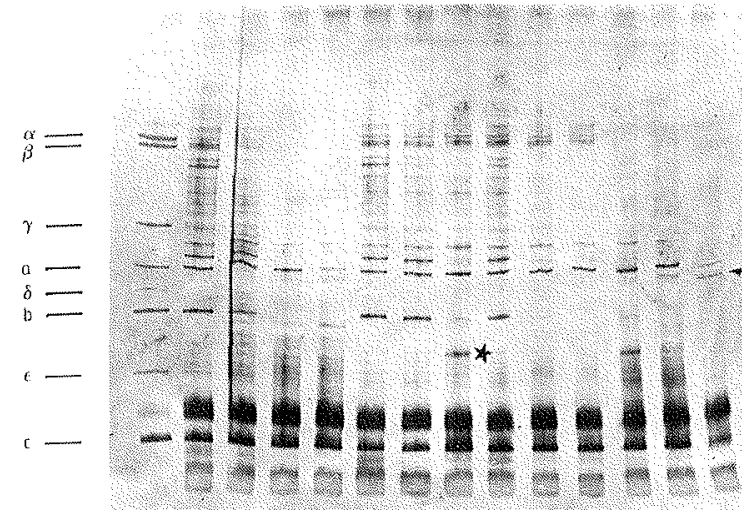

A B $1125 \begin{array}{llllllllll} & 4 & 5 & 6 & 7 & 8 & 9 & 10 & 11 & 12\end{array}$

Fig. 3. Proteolytic treatment of $F_{0}$ subunits in $F_{1}$-depleted membranes. $F_{1}$-depleted membranes of $E$. coli were prepared separated $F_{1} F_{0}$, and lane $B$, separated $F_{1}$-depleted membranes. The proteinase concentrations, increase in the samples from left to right for V8 (lanes 1-3), chymotrypsin [4-6], trypsin [7-9] and subtilisin [10-12]. The star indicates the digestion product obtained with chymotrypsin. The arrow indicates the possible cleavage product from subunit $a$

einases. $\mathrm{F}_{1}$ binding and ATP-dependent $\mathrm{H}^{+}$translocation were lost after digestion, indicating a binding activity of the extramembranous part of the $13.5 \mathrm{kDa}$ protein. Corresponding studies on the proteinase sensitivity of the $\mathrm{F}_{0}$-subunits from E. coli [49] gave similar results. Experiments were carried out using $\mathrm{F}_{1}$-depleted everted membrane vesicles from strain CM 2786, which overproduces ATP synthase about 5-fold (see also subsections IV A and B). Thus, the three $F_{0}$-subu hits could be in ${ }^{2}$-subunits could be easily idntified in whole membranes by SDSpolyacrylamide gel electrophoresis in combination with a silver stain method (Fig. 3). Subunit $b$ was most sensitive towards proteinase treatment. Trypsin, subtilisin and proteinase V8 produced small fragments, indicating that large portions of the protein were accessible to proteinases. These proteinases digeste straling that the polar domann of subunit $b$ extends to the cytoplasm in $E$. coli, since everted membrane vesicles were used. With chymotrypsin, however, a defined cleavage product of $M_{\mathrm{r}} 15000$ was observed, which remained firmly bound to the membrane, as treatment with high salt, urea or guanidine hydrochloride failed to remove this fragte nalyses it was shown that chymotrypsin did no cleave at the primary cleavage sites phenylalanine tyrosine, tryptophan or methionine, which are al located in the hydrophobic $\mathrm{N}$-terminal segment of the subunit $b$. Thus, cleavage had occurred about 25 residues away from the $\mathrm{C}$-terminus.

Under conditions where only subunit $b$ was degraded by protenases (see below), electrompelled $\mathrm{H}^{+}$-conduction (passive proton permeaported by Sone et at [48] after degrads were re ported by Sone et al. [48] after degradation of the $13 \mathrm{kDa}$ subunit of the PS-3 $\mathrm{F}_{0}$. But in contrast to PS-3, in E. coli $\mathrm{F}_{1}$ could be still bound to proteinase-treated membrane. The rebound ATPase activity was not sensitive towards DCCD and ATP-dependent proton translocating was not rethe por partituted. These results indicate that the polar part of subunit $b$ plays an essential role in coupling the functions of $\mathrm{F}_{1}$ with the $\mathrm{H}^{+}$translocation across the membrane. It is a distinct possibility that the proteinase-sensitive component at the in terphase of $F_{0}$ and $F_{1}$ from rat liver [50] also corresponds to the $E$. coli subunit $b$.

Subunit $a$ was not degraded by chymotrypsin and trypsin, while proteinase $\mathrm{V} 8$ and subtilisin at high concentrations were effective (Fig. 3). Subtilisin, at lower concentrations, digested all membrane proteins except subunit $a$ to products with $M_{\mathrm{r}}$ of less than 15000 . The appearance of the polypeptide with a $M_{\mathrm{r}}$ of 22000 at higher subtilisin concentrations was thus indicative for a cleavage product of subunit $a$. Possibly, the quite polar $\mathrm{N}$-terminal segment was attacked by the proteinase and, thus, might be located at the cytoplasmic side of the membrane.

Subunit $c$ was not or only slightly affected by any of the proteinases. Even prolonged incubation limes and high concentrations of proteinase did not lead to any extensive degradation (incubation time 5 days, at a ratio of proteinase to membrane protein of 1:5) [49]. Since subunit $c$, and especially the polar domain, is very resistant to proteolysis even in the denatured state, this result does not necessarily imply that the functional protein is completely inaccessible to proteinases. 
Loo and Bragg studied the effect of antiserum raised against subunit $c$ on proton conductance and $F_{1}$ binding in everted and right-side-out membrane vesicles of $E$. coli [51]. Antibodies added to everted membrane vesicles inhibited the proton conductance catalyzed by $F_{0}$. There was no effect when these antibodies were added to right-side-out vesicles.

At present, the antigenic site(s) of subunit $c$ are not determined. Computer analysis of the primary structure led to the prediction that the antigenic sites are located at the hydrophilic $\mathrm{N}$-terminus and the hydrophilic segment in the middle of the polypeptide chain [52]. In principle, it should be possible to identify the accessible fragments of subunit $c$ employing antibodies against defined peptide fragments.

\section{IIIC. Surface label}

In recent years, the chemistry of photoreactive labels has rapidly advanced [for review see Refs. 53-56]. One type of these reagents are lipophilic compounds, which distribute in the membrane and upon illumination form a highly reactive nitrene or such a group should react unspecifically with a broad range of amino acid side-chains. This requires that the half-life of the reactive intermediate be shorter than its rotation correlation time [55]. Only if labelling occurs randomly will all amino acid residues at the protein/lipid interface be detected, thus allowing a detailed mapping of the protein surface. So far none of the available photoreactive probes has none of the avalable phas been found to have an equ reactivity for all side-chains. Two types of hydrophobic label have been devised. The first group comprises small hydrophobic molecules which might randomly distribute in the lipid bilayer and thus can reach all residues which are in contact with the hydrophobic core of the bilayer Among a series of reagents iodonaphthylazide, iodophenylazide, adamantyldiazirine and 3-trifluormethyl-m-(iodophenyl)diazirine (TID) have been used most frequently [57-60]. Labelling was so far analyzed on the level of intact subunits of whole proteins, or large fragments [57-61]. The identification of

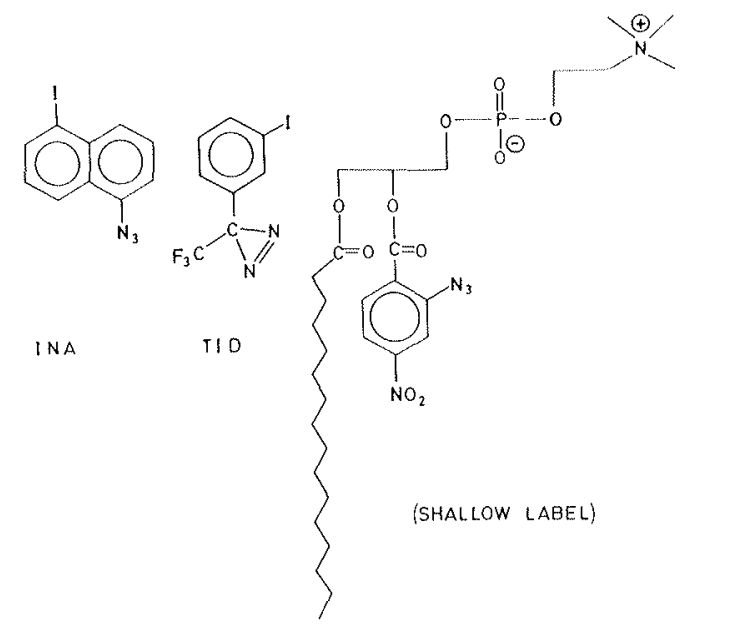

Fig. 4. Structure of the hydrophobic photorea
for the labelling of $F_{0}$. INA, iodonaphtylazide.

modified residues has not been reported so far.

The second group comprises phospholipid derivatives, bearing a phenylazidoprecursor, a phenyldiazirine [62-67], or a trifluoromethylphenyld azirine [68]. In these compounds, the photoreactive group is fixed and is expected to cross-link with defined regions of the protein. The "shallow label', shown in Fig. 4, will only label residues which are in proximity to the headgroup of the lipids. There are a few examples with phospholipid analogues where the attached label has been traced back to individual amino acids. The 'shallow label' has been used by Bisson et al. [69] to label the membrane surface of the cytochrome $c$ oxidase. The label has been traced back to amino acid residues, marking the beginning of one stretch of hydro phobic residues in subunit II of the complex. Ross et a [70] described the labell brane domain of glycophorin A with phospholipids, containing carbene precursors (aryldiazirine). They found that Glu-70 was the predominant site of cross-linking with phospholipid derivatives. Brunner and Richards [68] found a tryptophan as the major site of carbene and nitrene-generating phospholipid analogue in contact with gramicidin.

For the $E$ coli $\mathrm{F}_{0}$ labelling was studied with a photoreactive phospholipid analogue ('shallow probe') and the two small lipophilic reagents $\left({ }^{125}\right.$ I)iodonaphthylazide and $\left({ }^{125}\right.$ I)TID (Fig. 4) [71-73]. The probes bearing a nitrene precurso
INA

A B

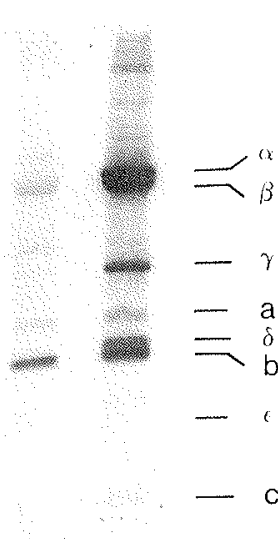

$F_{1} F_{0}$ $\frac{x}{0}$

Fig. 5. Reactivity of $\mathrm{F}_{0}$-subunit from $E$. coli towards membrane permeation photoreactive probes (Ref. 72; see also Hoppe, J. Brunner, J. and Jørgensen, B.B., unpublished data) (A) Isolated $F_{1} F_{0}$ dissolved in Aminoxid WS 35 buffer reacted with ( ${ }^{125}$ I)iodonaphthylazide. (B) Isolated $\mathrm{F}_{1} \mathrm{~F}_{0}$ dissolved in $2 \%$ SDS buffer reacted with [ ${ }^{125}$ ioconaphithylazide. (C) Isolated $\mathrm{F}_{1} \mathrm{~F}_{0}$ dissolved in Aminoxid wS35 buffer reacted with ( ${ }^{125}$ I)TID (D) $F_{1}$-depleted membranes from strain CM2786 reacted with ITD. After reaction whin he plabel, subunits were label was visualized by autordiography. The position of the individual subunits as determined by staining with Coomssic Blue is indicated. INA, iodonaphthylazide.

${ }^{125}$ I)iodonaphthylazide and the "shallow probe' exhibited a high selectivity, both on the level of whole subunits and on the level of individual amino acid residues.

In the functional enzyme, solubilized in the detergent Aminoxid WS 35, $\left({ }^{125} \mathrm{I}\right)$ iodonaphthylazide almost exclusively labelled subunit $b$, but not the other two hydrophobic subunits $a$ and $c$ (Fig. 5 ). With the subunits dissociated in sodium dodecyl sulfate, all subunits including the $F_{1}$ subunits

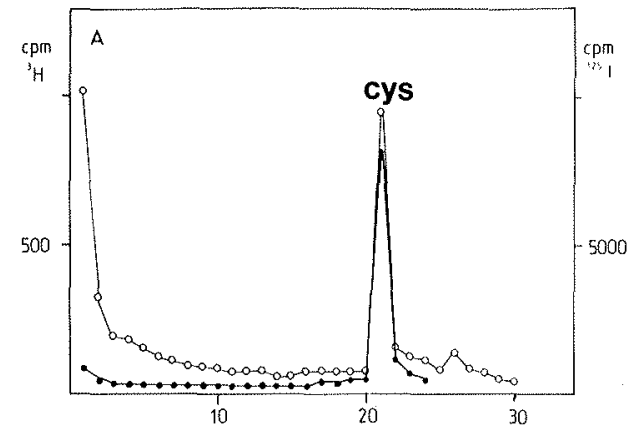

Fig. 6. Identification of amino acids of subunit $b$ labelled with [25I]iodonaphthylazide and the 'shallow probe'. Labelled subunit $b$ was isolated from $\mathrm{F}_{1} \mathrm{~F}_{0}$ by HPLC gel permeation chromatography, immobilized on phenylenedisothiocyanateactivated porous glass beads and sequenced $[71,72]$. Released PTH amino acids were analyzed for radioactivity. ${ }^{3} \mathrm{H}$-radioactivity from the phospholipid derivative

activity from [ ${ }^{125}$ I]iodonaphthylazide.

were labelled with the exception of subunit $c$ Similarly, the 'shallow probe', also a precursor of a nitrene, reacted only with subunit $b$ in the $\mathrm{F}_{1} \mathrm{~F}_{0}$ complex reconstituted into proteoliposomes. Modified amino acid residues were identified by isolation of labelled peptides and amino acid sequencing. Both probes reacted only with the hyhyN-terminal segment of subunit $b$. The distribution of radioactive label among the sequenced amino acid residues is shown in Fig. 6. ( ${ }^{125}$ I)iodonaphthylazide labelled almost exclusively Cys-21. Also the 'shallow probe' reacted predominantly with this residue. In addition, Trp-26 which is close to Cys-21, received a label, and possibly the first three residues including $\mathrm{Asn}_{2}$ at the $\mathrm{N}$ terminus were attacked. But with the latter, a clear interpretation was not possible due to the high radioactive background in the first step of Edman degradation. In conclusion, nitrene-generating hydrophobic precursors seem to be insufficient for a detailed map of the surface of membrane domains of proteins which are mainly composed of aliphatic residues.

The insufficiency may result from the rather long lifetime of the nitrene. Furthermore, arylnitrenes may undergo intramolecular rearrangements leading to long-lived electrophilic species [74]. Cysteines, as the most potent nucleophiles 
among the amino acid residues, may act as a sink for such intermediates. The situation appears to be slightly better with the phospholipid, where diffusion of the reactive species is restricted.

Carbenes are much more reactive than nitrenes. They even insert into $\mathrm{CH}$ bonds of the aliphatic chain of phospholipids [67]. The aryldiazirines represent one type of carbene precursor. As a side-reaction of photolysis, these compounds undergo a rearrangement to the corresponding diazoisomer, wich specifically will esterify carboxy groups. The problems with this type of precursor have been problems with this type
discussed recently [70].

To circumvent this problem, trifluoromethyldi-
discussed recently [70]. azirines have been introduced by Brunner [68] The undesired diazoisomer is stabilized by the strong electron-withdrawing trifluoromethyl group, and esterification by the diazoisomer is thus aligible. Fig $5 \mathrm{C}$ and $\mathrm{D}$ by the carbene, roughly according to their protein by the carbene, roughly according to their protein mass. In $F_{1}$-depleted membranes, the same label-
ling pattern of subunits $a$ and $b$ is observed, the ling pattern of subunits $a$ and $b$ is observed, the
labelling of subunit $c$ is obscured by the large amount of labelled phospholipids.

Labelling patterns were recorded with (i) isolated ATP synthase $\left(\mathrm{F}_{1} \mathrm{~F}_{0}\right)$, (ii) $\mathrm{F}_{1}$ depleted membranes from strain $C M 2786$ which overproduces the ATP synthase, and (iii) subunits denatured in a $2 \%$ SDS-solution.

${ }^{125}$ IJTID labelled subunits $b$ and $c$ could be isolated and the modified residues could be determined. Sequence analysis was performed by automated solid phase Edman degradation. Released PTH amino acids were identified by layer chromatogaphy and associated 1 -radioaclivity was measured as shown in Fig. 7A-C. The reaction product with $\left[{ }^{125}\right.$ I]TID was further analyzed by autoradiography of the thin-layer plates. This allowed the identification of labelled amino acid residues even over a high backgroun and an overlap from the preceding amino acid residue.

Proteinchemical analyses of TID-labelled subunit $b$ by $\mathrm{CNBr}$ cleavage showed that more than $98 \%$ of the label was attached to the N-terminal segment. Fig. 7A, B depict the labelling of individual amino acid residues after reaction of $\left({ }^{125}\right.$ I)TID with the isolated complex $F_{1} F_{0}$ - or $F_{1}$-depleted
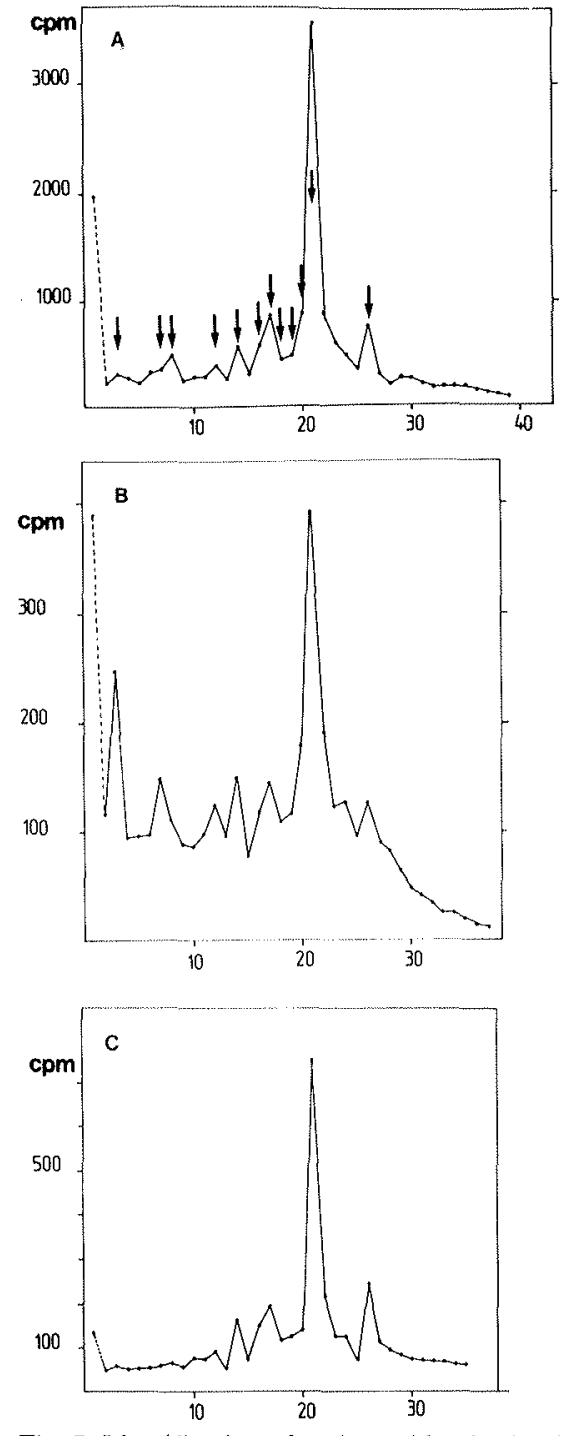

Fig. 7. Identification of amino acids of subunit $b$, labelled wit ${ }^{12.5}$ IJTID (Hoppe, J., Bronner, J. and J Jrgensen, B. B., unpub by HPLC . Alter labelling, subunit $b$ was isolated from $F_{1} F_{0}$ by $\mathrm{HrLC}$ gel pernealion chromagraphy. For $\mathrm{F}_{1}$-depleted gel and the band corresponding to subunit $b$ was eluted from the gel strip. Subunit $b$ from (A) $\mathrm{F}_{1} \mathrm{~F}_{0}$ in Aminoxid WS 35 buffer, (B) $F_{1}$-depleted membranes, (C) $F_{1} F_{0}$ in SDS-buffer. Arrows indicate labelled amino acid residues, identified by autoradiography of the PTH amino acids after thin-layer chromatography.

membranes. In the $\mathrm{N}$-terminus of subunit $b$, again Cys-21 received the bulk label. But other amin acids are significantly labelled. Most interestingly,
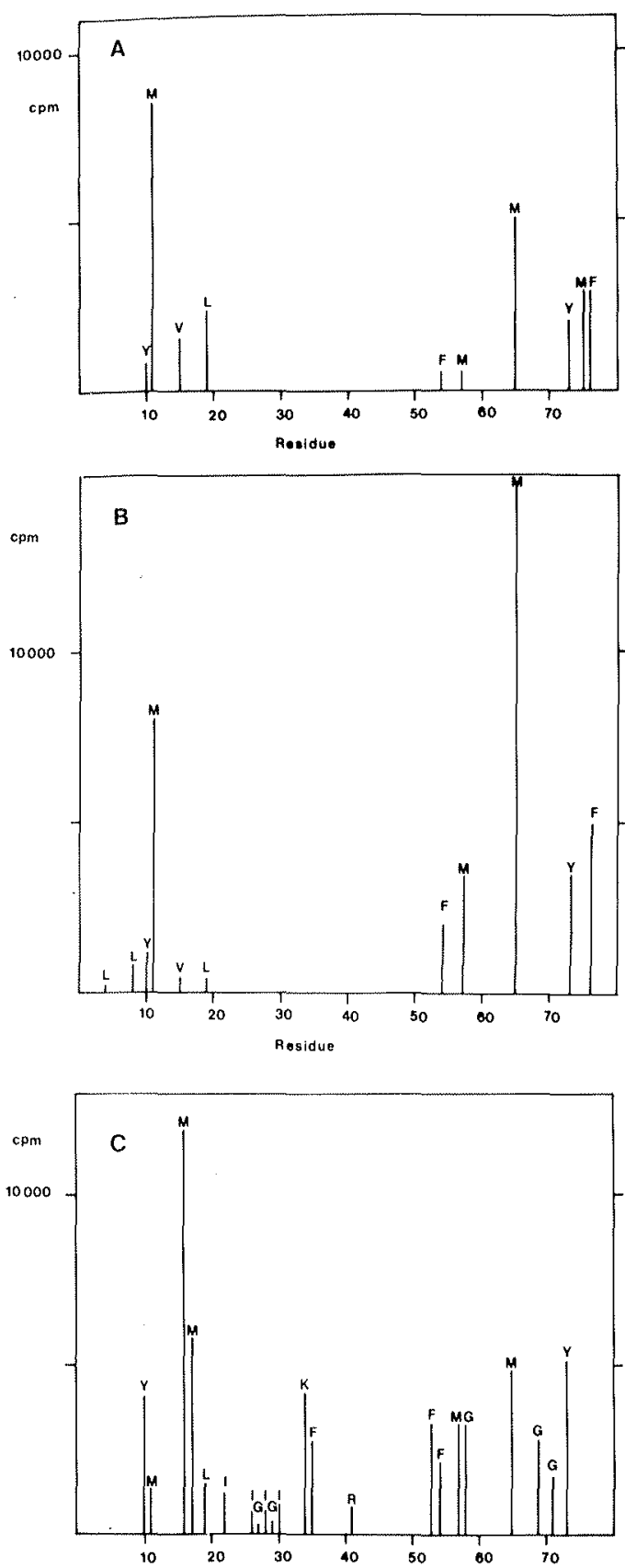

Fig. 8. Labelling of individual amino acids of subunit $c$ by ${ }^{125}$ I)TID (Hoppe, J., Brunner, J. and J $\phi$ rgensen, B.B., unpubthe wata). Labelling was determined by sequencing the who ${ }_{125}$ I-radioactivity to glass beads. Samples were analyzed for autoradiography of the released PTH amino acids after thinlayer chromatography. The amount of label bound to an amino acid side-chain was then calculated, assuming a repetitive yiel of $95 \%$ for each cycle of Edman degradation. (A) Subunit
Leu-3, Ile-7, Leu-8, Trp-26 and all residues from Phe-14 to Cys-21 were labelled as confirmed by milar labelsegment was obtained after reaction of $\left[{ }^{125}\right.$ I]TID with isolated subunit $b$ in SDS-solution (Fig. 7C). Thus, most of the amino acid residues of the membrane-integrated $\mathrm{N}$-terminus of subunit $b$ are freely accessible from the lipid phase.

After reaction of $\left[{ }^{125}\right.$ I]TID with a functional $\mathrm{F}_{0}$ $\left(F_{1}\right.$-depleted or $\left.F_{1} F_{0}\right)$, only a few residues of subunit $c$ were attacked (Fig. 8A-B) in contrast to the multiple labelling in the $\mathrm{N}$-terminal segment of subunit $b$. Labelling is restricted to four to six residues in the $\mathrm{N}$-terminal segment and to five to six residues in the $\mathrm{C}$-terminal segment. No labelling occurred in the middle of the polypeptide chain from positions $20-52$, despite the fact that the sequence from residues $20-33$ is highly enriched in hydrophobic residues, and thus is a possible candidate for a membrane-embedded segment. The labelling pattern changes dramatically if $\left[{ }^{125}\right.$ I]TID is reacted with the SDS-solubilized isolated subunit $c$ (Fig. 8C). Labelled residues are distributed over the whole length of the polypeptide, including the hydrophobic segment 20-30, which was not labelled in the functional subunit $c$. Apparently, these residues are shielded by other protein segments in functionally assembled subunit $c$.

In the functional subunit $c$, the ${ }^{125}$ IJTID modified residue at the $\mathrm{N}$ - and $\mathrm{C}$-terminals exhibit a remarkable repeat. They occur at positions 4,8 , $10,11,15,19$ and 53, 57, 65, 73, 76 [74]. Such $n+3$ or $n+4$ patterns are typical for residues located on the same side of an $\alpha$-helix.

\section{IIID. Cross-linking experiments}

The subunit contacts in the E. coli $\mathrm{F}_{0}$ were studied with the isolated complex $F_{1} F_{0}$ by crosslinking experiments. Fluoronitroazidophenyl was used, which in the first step binds by a nucleophilic displacement reaction to the side-chains of cysteine, lysine, tyrosine or histidine. Subsequently,

from $F_{1} F_{0}$ in Aminoxid WS 35 buffer; (B) subunit $c$ in $F_{1}$-depleted membranes; (C) subunit $c$ in an SDS solution. 
$\delta$-subunits or any of the other subunits (Fig. 9). In addition, cross-linking products containing subunit $b$ with an apparent $M_{i}$ of 24000 and 41000 were found which might be dimers of subunit $b$ with subunit $a$ and subunit $c$. Two products with an $M_{\mathrm{r}}$ of about 70000 were found. Most likely, subunit $b$ was crosslinked with the $\mathrm{F}_{1}$ subunits $a$ and $\beta$.

Apparently, the $b$-subunit has multiple contact with other subunits, and, therefore, should be located in the center of the complex as also suggested by analysis of the protein sequence [29]. Futhermore, the appearance of a cross-linked subFuthermore, the appearance of a cross-linked sub-
unit $b$ dimer substantiates findings that two subunit $b$ dimer substantiates findings that
units $b$ are present in one $\mathrm{F}_{0}$-complex.

\section{IIIE. Circular dichroism measurements}

The secondary structure composition of the proteolipid subunits isolated from E. coli and Neurospora crassa (Table II) has been studied by circular dichroism measurements $[6,75,76]$. The spectra were recorded after dissolution of the protein in were recorded after dissolution of the protein in
trifluoroethanol, SDS or octylglucoside, as well as after reconstitution with different preparations of small phospholipid vesicles. By means of a computer program, the CD spectra of pure $\alpha$-helices of different length, of pure $\beta$-sheet, and of $\beta$-turn very high content of $\alpha$-helix was calculated from all measurements. For the $N$. crassa protein, this high $\alpha$-helical fraction seemed to be almost unaffected by the different environments. In the subunit $c$ from $E$. coli, however, there was a more significant decrease in the $\alpha$-helical content, especially in the length of the $\alpha$-helical segments upon transition from ic solvents to the lipid phase. etween the two sets of data was the calculated content of $\beta$-sheet. For the $N$. crassa protein incorporated into lipid vesicles, no $\beta$-sheet was calculated. In contrast to the $E$. coli subunit $c$, about $20 \% \beta$-sheet was reported. It is questionable whether these differences are significant since the accuracy in the estimation of $\beta$ sheet eant, since content in the presence of a high fraction of $\alpha$-helix
is quite low.

Most remarkably, the $\alpha$-helical content in the large cyanogen bromide fragment from $E$. coli subunit $c$ was considerably reduced. This suggests

TABLE II

SECONDARY STRUCTURE COMPOSITION (FIGURES IN \%) OF THE PROTEOLIPID SUBUNIT FROM E. COLI (A) AND N. CRASSA (B) IN VARIOUS SOLUTIONS [6,75,76]

\begin{tabular}{lllllr}
\hline Solution & \multicolumn{4}{l}{ Content in } & \multicolumn{3}{l}{} \\
\cline { 2 - 6 } & $\alpha$-Helix & $\beta$-Sheet & Turn & Random & $\bar{n}$ \\
\hline A Trifluoroethanol & 76.6 & 15.2 & 8.2 & 0 & 24.6 \\
10\% 2-Chloroethanol & 66.4 & 18.2 & 15.4 & 0 & 8.5 \\
Phospholipid vesicles 1 & 67.6 & 32.4 & 0 & 0 & 5.3 \\
Phospholipid vesisles 2 & 71.8 & 24.4 & 0 & & 11.9 \\
Sodiumdodecylsulfate & 44.6 & 35.3 & 0 & 20.1 & 25.0 \\
Octyiglucoside & 53.6 & 20.1 & 0 & 25.8 & 25.0 \\
B6 in 10\% 2-chloroethanol & 38.5 & 34.3 & 6.9 & 20.3 & 5.6 \\
B Vesicle I & 69.0 & 0 & 15.0 & 16.0 & \\
Vesicle I & 69.0 & 0 & 12.0 & 19.0 & \\
Vesicle II & 83.0 & 0 & 17.0 & 0 & \\
Vesicle III & 73.0 & 0 & 16.0 & 10.0 & \\
Trifluoroethanol & 72.0 & 0 & 0 & 28.0 & \\
Octylglucoside & 83.0 & 13.0 & 4.0 & 0 & \\
Solubilized sodium dodecyl sulfate & 60.0 & 18.0 & 0 & 22.0 & \\
\hline
\end{tabular}

that non-helical segments of the protein reside in this fragment, which contains the conserved hydrophilic stretch, as well as the cluster of conserved glycine residues. It is uncertain at this time in how far the isolated proteolipid retains the secondary structure elements of the functional $\mathrm{F}_{1} \mathrm{~F}_{0}$-integrated protein. It has to be noted, however, that the secondary structure derived from $\mathrm{CD}$ measurements roughly compares with secondary structure predictions $[6,77-80]$.

\section{Genetics of $F_{0}$}

IVA. General aspects

The arrangement of the genes coding for the subunits of $F_{0}$ and $F_{1}$ is completely different for the enzyme from the plasma membrane of $E$. coli and from mitochondria or chloroplasts of eukaryotic cells. As described in section II (Fig. 1) and reviewed in detail elsewhere, the E. coli $\mathrm{F}_{0} \mathrm{~F}_{1}$ is coded for by an operon of eight genes $[1,12,13]$. The genes of $F_{0}$ preceding the $F_{1}$ genes are transcribed in the order $a, c, b$. The nucleotide sequence has been determined [14-23]. A few subunits of mitochondrial $F_{0}$ are coded for on mitochondrial DNA. In all analysed organisms subunit $a$ has been located on mitochondrial DNA and the sequence has been determined [81-84]. In yeast, subunit $c$ (proteolipid subunit 9 ) is encoded on mitochondrial DNA [85], in other organisms in the nucleus [82-86]. The other genes have not been located, so far. With one possible exception they appear to be localized in the nucleus, as deduced from biosynthetic studies [89]. The chloroplast enzyme is coded for to a large part on chloroplast DNA. Genes for $F_{1}$ subunits $\alpha, \beta, \gamma$ and $\epsilon$, and for $F_{0}$ subunits $a$ and $c$ have been localized [87] in the organelle, and for some of them the sequence has been determined [90,91]. From biosynthetic studies, it can be concluded that only the genes for the $F_{1}$ subunit $\delta$ and $F_{0}$ subunit $b$ are located in the nucleus [92].

Mutants defective in ATP synthase can be detected only in facultative anaerobic organisms which in the absence of the ATP synthase, survive by substrate-level phosphorylation. For all the $F_{1} F_{0}$ genes of the atp operon in $E$. coli mutations are known which result in a defective ATP synthase, This provides an excellent proof that the eight genes code for vital subunits of the enzyme. The genes have been designated unc $\mathrm{A}$ to unc $\mathrm{H}$ or atp A to atp $\mathrm{H}$ by different laboratories. In addition, inhibitor-resistant strains of $E$. coli are known which all are affected in the atp $\mathrm{E}$ (unc $\mathrm{E}$ ) gene, coding for subunit $c$. In yeast, the mitochondrial

dimer, since no reaction product with a similar $M_{\mathrm{r}}$ was found with antibodies directed against the 


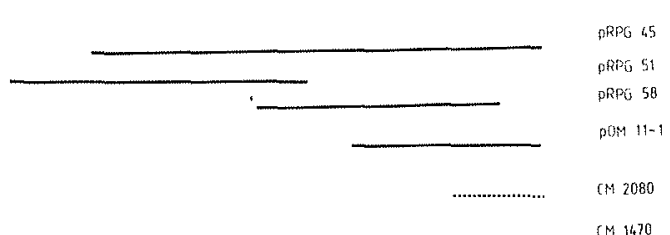

Fig. 10. Plasmids expressing selected genes of the $a t p$ operon $E$. coli and strains carrying defined deletion in the atp operon. $\square$, coding region for the subunits $a, c, b$; - , indcates the cloned region of the atp operon in the respective plasmid $[101,102] ; \ldots . . .$. , indicates the deleted region in the two strains [13]

genes encoding subunit $a$ and $c$ are covered by mutations leading to defective ATP synthase (Pho mutations leading to defective AT inhibitors (Oli I I, Pho II), or resistance towards inhibitors (Oli III, Oli IV) [93-96]. The corresponding nuclear subunit $c$ gene in $N$. crassa can also be mutated to an allele leading to oligomycin resistance [97].

In $E$. coli, phages and plasmids have been isolated containing all $F_{0} F_{1}$ subunit genes, i.e., the whole atp operon whole atp operon [98-101]. This allows, tor example, the construction of strains where the level of $\mathrm{F}_{0} \mathrm{~F}_{1}$ in the membrane is increased several-fold [48]. The membranes of such overproducing strain offer advantages for structural studies. Furthermore, plasmids are now available containing only segments of the atp operon [101,102]. Thus, a subset of subunits or in certain cases even a single subset if subuits devel in the cell (Fig 10). The latter plasmids are useful, especially when introduced into mutant strain where large parts of the atp operon are deleted or not expressed.

In principle, a mutation in a subunit gene can affect the properties and function of $F_{0}$ at several levels. (i) The mutation may prevent the biosynthesis of a subunit or its integration into the synthesis of a subunit or ins ingeration in to the bly of $F_{0}$, even if the mutated subunit is integrated into the membrane. (iii) A mutation may affect the function of $F_{0}$, even if the altered subunit is assembled into $F_{0}$.

In the following, mutant strains will be de- scribed, where both the genotypes and the phenotypic alterations have been studied in some detail.

\section{IVB. Deletion mutants and plasmids}

The deletion mutants of E.coli, compiled in Fig, 10, allow the study of membranes in which selected $\mathrm{F}_{0}$ subunits are missing. Strain CM 2080, characterized in some detail, has a deletion of about 500 basepairs at the start of the subunit $a$ gene [102]. Membranes of this deletion mutant conta [102]. Membranes of this delen if isolate $F_{0}$ subunits $b$ and $c$, but only if isolated from exponentially growing cells. If membranes are prepared from mutant cells in the stationary growth phase, only subunit $c$ is detected. Most likely, subunit $b$ was proteolytically degraded in stationary phase cells [49]. As described in subsection IIIA, the large polar domain of subunit $b$ is easily attacked by proteinases in vitro [49]. Another deleCM 1470 has a large deletion including genes of subunits $a, c, b, \delta$ and part of $\alpha$ [13] The membrane of this strain is devoid of all $\mathrm{F}_{0}$ subunits.

In other types of mutant, a $M u$ phage has been inserted at various points of the atp operon. The inserted phage DNA prevents the efficient transcription of all genes polar mutations, therefore, result in membranes which are devoid of certain subunits. One example is the strain AS 12 (Table IV) [103,104], where the $M u$ phage is inserted in the atp A gene coding for $F_{1}$ subunit $\alpha$. Accordingly, $F_{1}$ subunits $\alpha, \gamma, \beta$, and $\epsilon$ are not expressed. In addition, $F_{0}$ subunit $b$ is not present in the membrane. Possibly, the defect in $F_{1}$ ubunit $b$ or faciliates a proteolytic degradation.

Finally, several segments of the atp operon have been cloned on plasmids. One plasmid, pOM 11 , contains the intact coding sequence for subunit $a$ [13]. A functional subunit $a$ is expressed from the cloned gene, since it complements the deletion of the subunit $a$ gene in strain CM 2080. Another coding for subunits $b$ and $\delta$. The cloned genes are expressed. The plasmids have been introduced into the deletion mutant $\mathrm{CM} 1470$, where all $\mathrm{F}_{0}$ genes are missing [13]. The strains obtained contain in the membrane either only $\mathrm{F}_{0}$ subunit $a$ or only subunit $b$.
TABLE III

ACTIVITIES OF Fo IN unC-MUTANTS LACKING INDHVIDUAL $F_{0}$ SUBUNITS [102]

Strains: A 1 wild-type; CM 1470 and CM 2080 deletio mutants; the presence of subunit $b$ depends on growth phase $(\log =\operatorname{logarithmic}$, stat $=$ stationary phase); AM 12 and DO $10 / 6$, polar 0 PRPG 51, phemid with structural gene for for subunit $a$; pRPG
subunits $b$ and $\delta[102]$.

\begin{tabular}{|c|c|c|c|}
\hline Strain & $\begin{array}{l}F_{0} \\
\text { subunits }\end{array}$ & $\begin{array}{l}\mathrm{H}^{+} \text {con- } \\
\text { duction }\end{array}$ & $\begin{array}{l}F_{1} \\
\text { binding }\end{array}$ \\
\hline A 1 & $\begin{array}{lll}a & b & c\end{array}$ & + & + \\
\hline DG $10 / 6$ & $a \quad b$ & - & + \\
\hline CM $2080(\log )$ & b c & - & + \\
\hline AM 12 & a $\quad$ c & - & + \\
\hline CM $1470+$ pOM 11-1 & $\mathrm{a}$ & - & + \\
\hline CM $1470+$ pRPG 51 & $\mathrm{~b}$ & - & + \\
\hline CM 2080 (stat) & $\mathrm{c}$ & - & - \\
\hline CM 1470 & & - & - \\
\hline
\end{tabular}

The membranes of all these strains, in which ingle or multiple $\mathrm{F}_{0}$ subunits are genetically deleted, have been analysed for their capability to

TABLE IV

E. COLI MUTANT STRAINS WITH DEFECTIVE OR DCCD-RESISTANT Fo

n.d., not determined.

\begin{tabular}{|c|c|c|c|c|c|c|c|}
\hline $\begin{array}{l}\text { Genotype } \\
\text { or strain }\end{array}$ & $\begin{array}{l}\text { Affected } \\
\text { subunit }\end{array}$ & $\begin{array}{l}\text { Amino acid } \\
\text { exchange }\end{array}$ & $\begin{array}{l}\text { Complemen- } \\
\text { tation: } \\
\text { dominant }(+) \text {, } \\
\text { recessive }(-)\end{array}$ & $\begin{array}{l}\text { Presence in } \\
\text { the membrane }\end{array}$ & $\begin{array}{l}\mathrm{H}^{+} \text {conduc- } \\
\text { tion }\end{array}$ & $\begin{array}{l}\text { ATPase acti- } \\
\text { vity }\end{array}$ & Ref. \\
\hline DG $25 / 3$ & $a$ & n.d. & - & n.d. & - & + & 105 \\
\hline $\begin{array}{l}\text { DG } 25 / 9 \\
\text { unc F } 469\end{array}$ & $\begin{array}{l}b \\
b\end{array}$ & $\begin{array}{l}\text { n.d. } \\
\text { n.d. }\end{array}$ & $\begin{array}{l}- \\
-\end{array}$ & + & + & + & $\begin{array}{r}105 \\
12\end{array}$ \\
\hline $\mathrm{DG} 7 / 1$ & c & $\mathrm{Asp}_{61}-$ Gly & + & + & - & + & 108 \\
\hline DG $18 / 3$ & c & $\mathrm{Asp}_{61}-\mathrm{Asn}$ & + & + & - & + & 109 \\
\hline DG $27 / 10$ & $c$ & $\mathrm{Ala}_{21}-\mathrm{Val}$ & - & + & - & + & $\begin{array}{l}\text { (Hoppe, J., } \\
\text { Schairer, H.U. } \\
\text { and Von Meyen- } \\
\text { burg, K. }\end{array}$ \\
\hline $\begin{array}{l}\text { unc E 463 } \\
(=\text { unc E 408) }\end{array}$ & $c$ & $\mathrm{Leu}_{31}-$ Phe & - & $-(+)^{\mathrm{a}}$ & $-(+)^{a}$ & $-(+)^{a}$ & 2,111 \\
\hline unc E 410 & c & $\mathrm{Pro}_{64}-$ Leu & + & + & - & + & 12,2 \\
\hline unc E 429 & $c$ & $\mathrm{Gly}_{23}$-Asp & - & - & - & - & 12,111 \\
\hline DC 13 & $c$ & $\mathrm{Ile}_{28}-\mathrm{Val}$ & n.d. & + & + & + & 115 \\
\hline DC 25 & $c$ & $\mathrm{Ill}_{28} \mathrm{es}^{\circ}-\mathrm{Thr}$ & n.d. & + & + & + & 115 \\
\hline
\end{tabular}

At high gene dosage rebind $\mathrm{F}_{1}$ and to conduct $\mathrm{H}^{+}$[102] (Table III). brane which is devoid of subunit $c$ due to a point mutation in the atp $\mathrm{E}$ (unc E) gene (see below). The results are summarized in Table III. The subsets of $F_{0}$ subunits. None of the $F_{0}$ subunits alone and none of the combinations of two $F_{0}$ subunits allows $\mathrm{a}^{+}$conductance across the membrane. Subunit $a$, as well as $b$, each present ing of $F_{1}$, while subunit $c$ alone does not. Accordingly, each pairwise combination of two $F_{0}$ subunits allowed a rebinding of $F_{1}$ to the membrane. The observed physical binding of $F_{1}$ to incomplete $F_{0}$ must be different from the binding to intact $F_{0}$. proton conductance is abolished in the incomplete

IVC. Point mutations

IVC-1. Mutants with defective $F_{0}$

All mutant strains compiled in Table IV revert Also included in these studies was a mutant memmembranes of these strains comprise all possible individually in the membrane, promote the bindThe rebound $F_{1}$-ATPase is active, although the 
readily, and consequently originated from single point mutations [12,105-112]. The mutational events in genes for subunit $a$ and $b$ have not yet been identified. Several amino acid substitution in the subunit $c$ gene have been determined by amino acid sequence analysis of the mutant protein or nucleotide sequen nucleotide sequence analysis of the mutated gene [107-111]. Remarkably, most of the subunit $c$ mutations are dominant over the wild-type allele [106,113]. A few subunit $c$ mutations, and all analysed mutations in genes for subunit $a$ and $b$, are recessive [12]. The dominant character of many subunit $c$ mutants is explained most probably by [113]. $\mathrm{F}_{0}$ contains $6-10$ subunit $c$ polypeptides which function in an interdependent way. Thus, in a diploid situation mutated subunit $c$, which is still assembled into $\mathrm{F}_{0}$ will inactivate most part of the available wild type subunit $c$. Accordingly, such dominant mutation in subunit $c$ do not interfere with the assembly in subunit $c$ do no presive mutations ap parently are defective in assembly. Negative complementation should occur either not at all or to lesser extent with mutations in genes for subunits $a$ and $b$, which exist in $\mathrm{F}_{0}$ as single or dimeric copies, respectively.

In some of the compiled mutant strains, the affected subunit is not present in the membrane. No direct information is available on the subunit $a$ mutant. This extremely hydrophobic protein could not be analyzed by two-dimensional gel electrophoresis, and antibodies are not yet available. Effects in subunit $b$ mutants are difficult to interpret at the moment. The membrane of atp $\mathrm{F}$ mutan DG $25 / 9$ contains termined by immunological techniques (Friedl, P., unpublished data). This mutant has a leaky phenotype, since ATP-dependent protontranslocation is partially retained [105]. A similar phenotype has been described recently for another atp $\mathrm{F}$ mutan [113] In strain unc F 469 subunit $b$ was not cted when whole membranes were analysed by two-dimensional gel electrophoresis [12]. Since subunit $b$ is extremely prone to proteolytic degradation, as described above, it is uncertain whether the mutation prevents integration into the membrane or whether a defective assembly result in a proteolytic degradation. Tentatively, it may be concluded that the latter strain is assembly-defec- tive, whereas in mutant DG $25 / 9$ subunit $b$ is assembled and thus protected from degradation. The situation is better defined in subunit $c$ mutants. In two strains, the mutation interferes with the integration of the polypeptide into the membrane. This is due to a substitution of Leu-31 by phenylanaline (unc E 463) and Gly-23 by aspartic acid (unc E429). [111]. The mutant subunit $c$ containing Phe-31 is forced into the membrane, and a functional $F_{0} F_{1}$ originates, if the mutant gene is present at high copy number. This is not true for mutant subunit $c$ containing Asp-23, i.e., a highly polar carboxyl group [111].

Of particular interest is the amino acid substitution of Ala-21 by valine (DG 27/10) (Hoppe, J., Schairer, H.U. and Von Meyenburg, K., unpublished data). This mutant subunit $c$ is integrated into the membrane. The mutation is recessive, thus the mutant subunit $c$ is apparently not assembled Pro-64 by leucine is present in the membrane [2]. The mutant allele shows a partial dominance over the wild-type allele. This suggests that this mutation does allow the assembly into $\mathrm{F}_{0}[106,111]$.

Mutants DG $7 / 1$ and DG $18 / 3$ are both affected in the invariant DCCD-reactive aspartic residue 61 [107-110]. These mutations are dominant, and both mutant proteolipids are present in the membrane [113]. Thus, these alterations allow an assembly of the mutant protein into $\mathrm{F}_{0}$.

The membranes of all $\mathrm{F}_{0}$ mutants compiled in Table IV are tight for protons with the exception of unc $\mathrm{F}$ mutant DG 25/9. Thus, these mutations interfere with the $\mathrm{H}^{+}$conduction catalysed by $\mathrm{F}_{0}$. This applies for mutants where the assembly of $F_{0}$ is defective. The phenotype of these point mutants corresponds to that of deletion mutants, which have been discussed in detail above (Table III). But it applies also to those mutants where the mutated subunit apparently is assembled into $F_{0}$.

Of particular interest is the question of whether mutations in $\mathrm{F}_{0}$ subunits. The binding affinity of $F_{1}$ has not yet been quantitatively analysed. This may explain discrepancies reported for the rebinding of $F_{1}$ to $F_{0}$ from certain mutants by different groups $[102,106]$. Despite these uncertainties, the most surprising result is that in mutant strains with apparently assembled $F_{0}$, the binding of $F_{1}$ is altered [109]. The bound ATPase activity of $F_{1}$ is not inhibited by the mutant $F_{0}$, as one would expect in analogy to the inhibition by DCCDmodified $\mathrm{F}_{0}$ [114]. This is particularly puzzling in the case of mutant strains DG $18 / 3$ exhibiting an -61 by an sparagine [109]. This minimal alteration leads to the impaired binding of an $F_{1}$ whose ATPase activity remains fully active. In contrast, if $F_{1}$ is rebound to wild-type $F_{0}$ whose Asp-61 has been modified by DCCD, the ATPase activity is in hibited [114]. Thus, even subtle changes in 'funcional' residues lead to changes in the architecture the whole complex. This structural or conte mational effects are further indicated by the observation (Friedl, P., unpublished data) that subunit $b$ is more easily extracted from $\mathrm{F}_{0}$ of mutan strains DG 18/3 and DG 7/1 than from wild-type $\mathrm{F}_{0}$.

IVC-2. Inhibitor-resistant mutants

Dicyclohexylcarbodiimide-resistant mutant have been isolated from E. coli. Six mutant strain have been described in detail [107,115]. Measure ment of the inhibition of ATPase activity as well as ATP-dependent $\mathrm{H}^{+}$-translocation at various concentrations of DCCD revealed two classes of mutant strains [115]. Whereas the wild-type enzyme is inhibited half-maximally at $3-5 \mathrm{nmo}$ DCCD per mg of membrane protein, the enzym from the class-one and class-two mutants are in hibited half-maximally only at 30 and 200 $\mathrm{nmol} / \mathrm{mg}$, respectively. DCCD at higher concentration still binds specifically to subunit $c$ as revealed by sequence analyses. For type one, Ile- 28 was substituted by valine. In type two mutant protein, a threonine was found at position 28 Most likely, Ile-28 affected in all resistant mutant is part of the DCCD-binding site. Enzymic activities, such as ATPase activity and ATP-dependen $\mathrm{H}^{+}$translocation, of these mutants are comparable to the wild-type protein. These results provide indirect evidence that the protein folds back, bringing Ile-28 and Asp-61 into proximity.

The analysis of oligomycin-resistant mutan rom Saccharomyces cerevisiae and $N$. crassa revealed that two proteins may be involved in the inhibitor binding. Besides the subunit $c$ (proteo- lipid) [97], in yeast subunit 6, a 259-residue protein has been found to determine oligomycin sensitivit of the ATP synthase complex [81] (Fig. 12). Thi protein is homologous to subunit $a$ of the $E$. coli ATP synthase. Interestingly, the mutations in subunit 6 are located close to the small conserved region of the protein.

Four different amino acid exchanges leading to oligomycin resistance have been described for the yeast and three for $N$. crassa (proteolipid) $[97,116]$. All amino acid exchanges reside in the C-termina hydrophobic stretch and are clustered around the invariant DCCD reactive glutamic (aspartic) residue. It is a distinct posibility, that the amino acid residues altered in the resistant mutants are involved in the binding of oligomycin. Thus, these residues might be located at the lipid/protein interphase. Some of them result in a hypersensitivity towards DCCD. Both facts suggest that the binding sites for DCCD and oligomycin are overlaping.

\section{Functional aspects}

\section{VA. Evolutionary aspects}

In recent years, numerous proteolipid subunit from various organisms have been sequenced, as extensively reviewed elsewhere [6]. The proteins contain $70-82$ residues and all may be purified by chloroform/methanol extraction. They are extremely hydrophobic, containing only $16-25 \%$ polar residues, which explains their solubility in organic solvents.

Long hydrophobic stretches of about 25 amino acid residues are found both in the $\mathrm{N}$-terminal as well as in the C-terminal part of the sequence. This is reminiscent of the most thoroughly investigated membrane protein, the bacteriorhodopsin from Halobacterium halobium, where stretches of 25 hydrophobic amino acids are found to traverse the lipid bilayer most probably in an $\alpha$-helical conformation (Fig. 11)

A comparison of the sequences of the homologous proteolipid subunits revealed numerous conserved amino acid residues. These residues might be indispensible for function or the maintainance of a certain structure of the protein. In the middle of the N-terminal hydrophobic stretch four glycine 
residues are conserved (Gly-27, Gly-29, Gly-31, and Gly-33). Gly-42, Arg-45, Asn/Gln-46 and Pro-47 localized in the middle hydrophilic segment were also found to be invariant. In this segment the single conserved basic amino acid residue (Arg-45) occurs. The single invariant acidic amino acid residue is observed in the middle of the C-terminal hydrophobic stretch (position 65). With one exception (aspartic acid in E. coli), this amino acid is a glutamic acid. This acidic residue is flanked by two cons tion 62 and 66). At the C-terminus (position 80), a conserved phenylalanine was found.

There seem to be some specifically conserved residues either for the mitochondrial type or for the bacterial type of proteolipid. Lys-14 is typical for the mitochondrial proteins plus Rhodospirillum rubrum. For the same family also the following positions are occupied by an identical or isofunctional residue: Leu-16, Gly-17, Gly-19, Gly-24, Leu-39, Arg/Lys-50, Gly-60, Phe-61, Gly/Ala-68, Leu-69, Phe-70, Met/Val-73, Val-74 and Ala/Ser75. For the bacterial family the following residues are invariant or isofunctional: Ala-16, Ala-17, Ala/Gly-18, Gly-22, Leu-23, Ala/Gly-24, Ala/Ser-25, Lys-38, Glu-41, Glu-48, Phe-58, Ile/Leu-59, Val/Met-61, Leu-63, Val-64, Pro-68 and Ile/Leu-70.

The two analyzed 'chloroplast' proteins resemble more the bacterial ones. It is noteworthy that the proteolipids from spinach and wheat chloroplasts have the same amino acid sequence [90,91].

These clear differences between the 'oligomycin-sensitive' proteolipids and the 'bacterial' proteolipids could indicate a different environment and different interactions of the protein in the assembled $F_{1} F_{0}$. Reports on the higher complexity in the subunit composition of $F_{0}$ in mitochondria support this view $[4,123]$.

Amino acid sequences of proteins from other organisms homologous to subunit $b$ from $E$. coli ATP synthase have not been reported so far.

For subunit $a$, homologous proteins have been sequenced. DNA sequences of the respective gene have been described for $S$. cerevisiae, human, bovine and mouse [81-84]. Conserved residues are indicated in Fig. 12.

\section{$V B$. Chemical modification}

Group specific reagents are versatile tools for detecting essential residues in enzymes. Ideally, these reagents modify single amino residues.

The interpretation and validity of chemical modification studies thus heavily depend on the determination of the modified amino acid(s). Furthermore, direct correlation between the extent of the modification of a specific amino acid residue with function must be established.

The binding of $\left[{ }^{14} \mathrm{C}\right] \mathrm{DCCD}$ to subunit $c$ (proteolipid) in all analyzed organisms was rather specific and occurred at low concentration $(1-10$ nmol/mg membrane protein) $[6,118]$. Maximum inhibition was observed when only a fraction of the subunits was labelled, indicating a cooperative interaction of the subunits [26,27,118-123]. For the beef-heart ATP synthase, the existence of ]DCCD with a different affinity $[123,124]$ compared with the monomeric subunits has been demonstrated.

Sequence analyses revealed an acidic residue (glutamic acid, with the exception of $E$. coli where aspartic acid was found) as the target of DCCD. This residue is located in a homologous position in all ten analyzed proteolipids $[110,125]$.

The hydrophobicity of DCCD indicates that the acidic residue should be located in the lipid bilayer. This observation was confirmed by the use of the paramagnetic carbodiimide NCCD ( $N$ 2,2,6,6-tetramethylpiperidyl-1-oxyl)- $N^{\prime}$-(cyclohexyl) carbodiimide [126]. Ascorbate, a water-soluble agent did not reduce the signal-generating nitroFrom spin-spin interactions between the NCCD molecules bound to the protein, it was suggested that the proteins exist in a polymeric form, in which some of the monomers are located at a maximal distance of $15-20 \AA$ from each other Bound NCCD was firmly immobilized as rotation correlation of 3-4 $\mu$ s where determined. Reconstitution of the purified protein yielded a high mobility of 2-3 ns. Apparently, in this experiment

The high immobilization of NCCD in native
The polymeric structure was not reconstituted.

The high immobilization of NCCD in native
embrane may be caused by a rather tight fitting of the DCCD into a 'binding site' at the proteo-

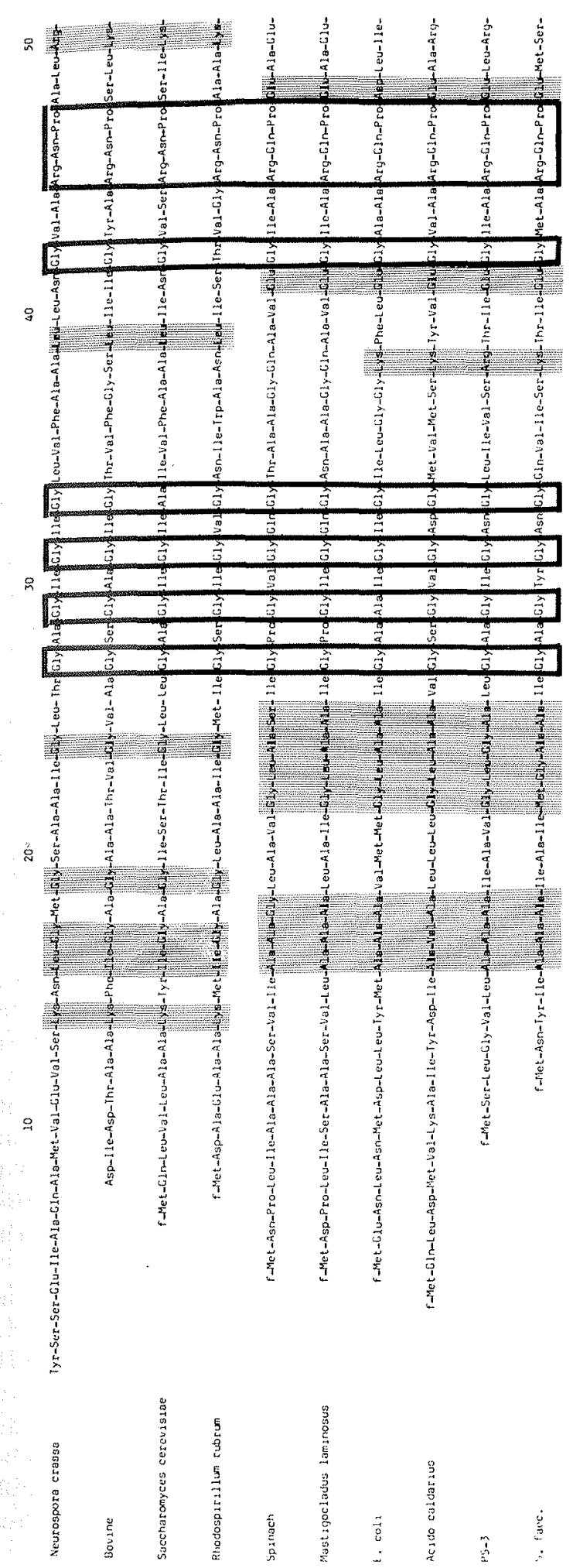

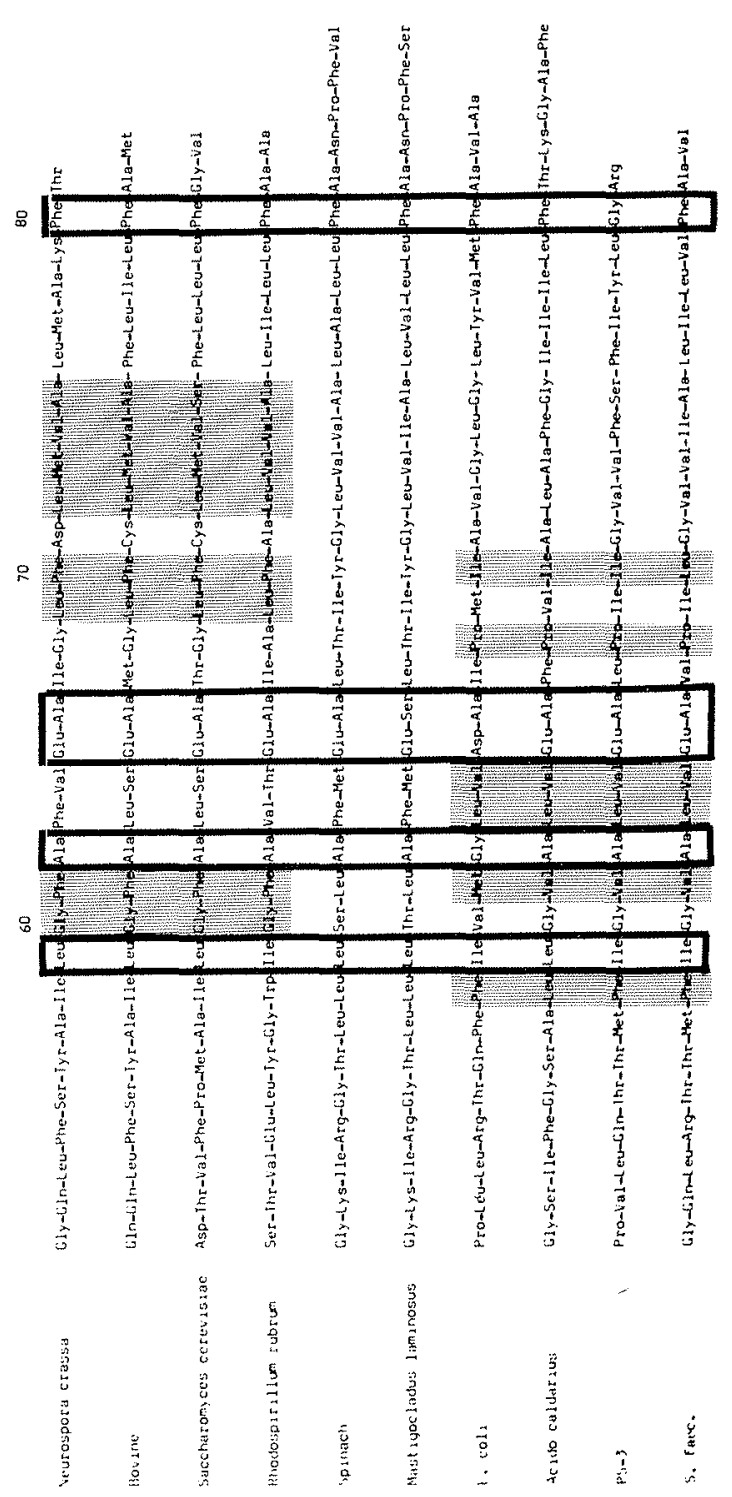


TABLE $V$

$I_{50}$ VALUES FOR SOME DCCD ANALOGUES

$\mathrm{R}-\mathrm{N}=\mathrm{C}=\mathrm{N}-\mathrm{R}^{\prime}, \mathrm{R}=$ cyclohexyl. $\mathrm{I}_{50}$ values for the analogues were obtained using incubation for 16 at $0^{\circ} \mathrm{C}$ at various inhibitor concentrations by measuring either ATPase activity or ATP-dependent $\mathrm{H}^{+}$translocation.

\begin{tabular}{lc}
\hline Compound R & $\begin{array}{l}\mathrm{I}_{50} \text { at } \mathrm{R}^{\prime} \\
(\mathrm{nmol} / \mathrm{mg} \\
\text { membrane } \\
\text { protein) }\end{array}$ \\
\hline Phenylethyl & 2 \\
Cyclohexyl & 5 \\
2,2,6,6-Tetramethylpiperidyl-1-oxyl & 5 \\
Phenyl & 20 \\
Adamantyl & $>200$ \\
\hline
\end{tabular}

lipid subunit. To obtain further information on the steric requirements, a small set of DCCD analogues was synthesized (Table V) (Hoppe, J., unpublished data). Apparently, it is difficult to assign the different effect of these reagents excluively to the size of the ligand, as the reactivity of e might be different But interestingly, the grade of substitution at the carbon atom in proximity of the carbodiimide seems to be crucial, as $N$-phenylethyl, $N^{\prime}$-cyclohexyl carbodiimide which contains a primary carbon atom was more reactive than DCCD itself. $N$-adamantyl$N^{\prime}$-cyclohexyl carbodiimide, containing a tertiary carbon atom, was not an inhibitor. Further hints for a tight fitting of the shape of DCCD to the surface of the proteolipid came from the analyses of DCCD-resistant mutants from E. coli [115].

There are data on the modification of tyrosine with tetranitromethane and iodine and arginines with phenylglyoxal in a $\mathrm{TF}_{0}$ preparation from PS-3 [127,128]. Modification of either of these residues [127, nhibited the proton conductance. Though modification of these residues has been demonstrated in the proteolipid, it is not possible to correlate the modification of these residues with the inhibition of functions, since the fate of corresponding residues in the other membrane subunits has not been studied.

VC. $\mathrm{H}^{+}$conduction in reconstituted subunits

So far, reconstitution experiments with isolated subunits have only been performed with the pro- teolipid subunit (subunit c). For the proteolipids extracted with butanol from lettuce chloroplasts or yeast mitochondria, a proton permeability of reconstituted lipid-proteolipid bilayers has been demonstrated [129-132]

Recently, single-channel conductance has been measured after reconstitution of the proteolipid from yeast into planar lipid bilayers [133]. Thus, in contrast to earlier studies, proton conductivities could be measured at a high-time resolution as function of voltage, protein concentration, $\mathrm{H}^{+}$ concentration and lipid composition. At the high $\mathrm{H}^{+}$concentration of about $10 \mathrm{mM}$ (corresponding to a $\mathrm{pH}$ of 22), single-channel conductivity has to a $\mathrm{pH}$ of 2.2), single-channel conductivity has been established.

Discrete current steps were measured, indicat ing the opening and closing of single channels. The observed ion path represents the operation of a single type of pathway with a mean conductance of $20 \mathrm{ps}$ and a life-time of $4 \mathrm{~ms}$. The single channels operate independently, since their occurrence obeys a Poisson distribution About 10 (100 ial and $\mathrm{pH} 22$ At $\mathrm{pH} 7$ and $100 \mathrm{mV}$, about 100 protons/s are transported by one channel. The channel was highly selective for protons as the conductivity for potassium, sodium and chloride ions was at least 1000 -fold lower.

Interestingly, most of the proteolipid molecules were not in an active state, explaining the low overall activity measured in previous systems [129-132]. The dependence of proton conductance on proteolipid concentration at $\mathrm{pH} 2.2 \mathrm{had}$ a molecularity of about 2 . The formation of channels from a large pool of proteolipid molecules thus involved a bimolecular reaction. In a most simple assumption, the associating species might meric proteolipid. In principle however, the reacting species might already be a dimer or trimer.

Between the bimolecular dependence of the proton conductance of the proteolipid concentration at $\mathrm{pH} 2.2$ and the linear dependence at $\mathrm{pH}$ 5.5 , there was a transition point at $\mathrm{pH} 4.5$ where the molecularities were much larger than 2 This suggests that the stabilization of the proton pathway at higher $\mathrm{pH}$ values involves the formation of structures larger than dimers. These associates were considered as oligomerized dimers.
But it could not be excluded that the increased conductivity at higher $\mathrm{pH}$ results from an in creased proton permeability of a single channel.

In the reported experiments, the $\mathrm{pH}$ induced conductance transition was only found in the presence of cholesterol and sufficiently high proteolipid concentrations. The interaction between proleolipid subunits therefore may not be su not be sufficiently onducting proteolipid oligomers in a biological membrane.

\section{Summary and Models}

VIA. Subunit a

If the sequence of 271 amino acid residues of subunit $a$ from $E$. coli is analyzed, seven segments can be discriminated where predominantly lipophilic residues are clustered (Fig. 12). In segment $1,3,4,6$ and 7, the hydrophobic character is mos pronounced. With the possible exception of seg ment 1 , no charged residues are present. The hydrophobic character of segments 2 and 5 is less pronounced. A charged residue occurs just in the middle of the segments. The hydrophobic profile of subunit $a$ is similar to the respective profiles of the mitochondrial proteins [3] if a deletion from residue 125 to residue 150 in the $E$. coli protein is assumed. It is noteworthy that the homology between the $E$. coli and the mitochondrial subunits is restricted to a short segment near the $\mathrm{C}$-termin corresponding to residues 189-219 of subunit from $E$. coli, whereas the rest of the polypeptide chains are completely unrelated. The similarity in he polarity profile suggests, however, that the general folding of the subunit has been conserved. The length of subunit $a$ as well as the occurrence of six or perhaps seven lipophilic segments are reminiscent to the amino acid sequence of bacterior to the a in has to be mentione bacteriorhodopsin, segnents $3,4,6,7$ bacteriorhodopsin, segments 3, 4, 6, 7 contain several basic and acidic residues and exhibit only a weak hydrophobicity $[43,46]$. Thus, in the $F_{0}$ subunit $a$, segment 2 , despite its relatively high polarity, might traverse the membrane. In yeast subuni 6 , two amino acid substitutions leading to oligomycin resistance bave been id The mutated residues would correspond id $[81]$.

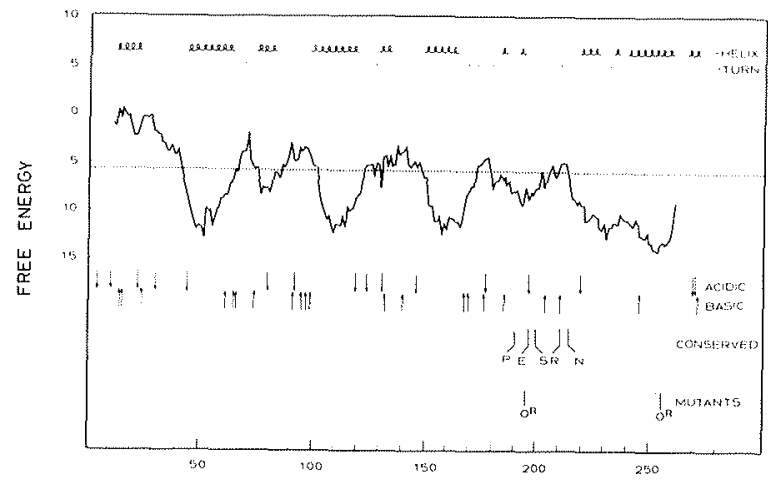

Fig. 12. Prediction of membrane-permeating segments and secondary structures in $F_{0}$ subunit $a$ from $E$. coll. $\alpha$-helical different prediction methods [77-80]. The free enced by four $(\mathrm{KJ} / \mathrm{mol})$ during a transition [rom a random coil in water to an $\alpha$-helix in the membrane were calculated for all amino acid sequence positions using the parameters given by Von Heijne [134]. The locations of acidic $(\downarrow)$ and basic $(\uparrow)$ residues are indicated by arrows. A proline residue and four polar residues conserved in the amino acid sequences of $E$. coli $\mathrm{F}_{0}$ subunit $a$ and mitochondrially coded $F_{0}$ subunit 6 from yeast [81] and mammals [82-84] are indicated by the one-letter code. Two amino acid exchanges leading to oligomycin-resistance $\left(\mathrm{O}^{\mathrm{R}}\right)$ were identified in $F_{0}$ subunit 6 from yeast $[81]$.

the middle of the hydrophobic segments 5 and 7 . These residues might be directly involved in the binding of oligomycin, and thus be located in proximity to each other at the lipid phase. But this straightforward conclusion is not possible if these mutated residues affect allosterically the oligomycin binding. This alternative will be discussed in detail with subunit $c$.

Subunit $a$ is heavily labelled by the membranesoluble carbene-generating label [25 ITTID [73] (cf. Fig. 5). Unfortunately, the modified amino acid residues could not yet be identified in this large hydrophobic protein. A rough quantitative evaluation of $\left[{ }^{125}\right.$ I]TID radioactivity bound to each of the three $F_{0}$ subunits (see Fig. 5) indicates that subunit $a$ is labelled twice as much as subunit $b$

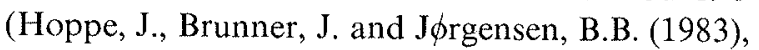
unpublished data). Accordingly, large parts of subunit $a$ are accessible from the lipid phase.

About 20 amino acid residues of subunit $a$ can be removed proteolytically from the cytoplasmic side with subtilisin (see Fig. 3) [49]. Since the $\mathrm{C}$-terminus is very hydrophobic, it is most likely that the $\mathrm{N}$-terminal end is susceptible to pro- 
teinases, and thus located at the cytoplasmic surface [49]. Taken that seven transmembrane segThe proteolytical breakdown products of subunit $a$ are difficult to analyze, even with membranes from an ATP synthase overproducing strain, due to the presence of many additional proteins. But at raised concentrations of proteinases bunit $a$ in the membrane decreases, indicating that other parts of the polypeptide chain are accessible to proteinases. It is conceivable that polar segment domains of subunits exposed at the cytoplasmic surface of the membrane are involved in the binding of $F_{1}$ as was observed in mutant strains containing only this $\mathrm{F}_{0}$ subunit.

VIB. Subunit $b$

The polarity profile of the sequence of 151 residues of subunit $b$ is striking in that about 30 hydrophobic amino acids are clustered at the $\mathrm{N}$ terminus (Fig. 13), whereas the rest of the polypeptide chain is very polar similar to a water-soluble protein. This imme in the membrane. In fact, all applied hydrophobic photoreactive probes reacted exclusively with this hydrophobic segment (Refs. 71 and 72, see also Hoppe,

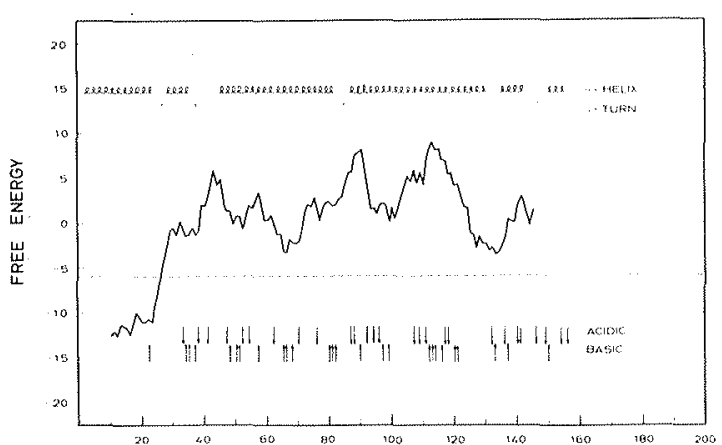

Fig. 13. Prediction of membrane-permeating segment and secdifferent prediction methods $[77-80)$. The free-energy gains for $\alpha$ transition from a random coil in water to an $\alpha$-helix in the using the parameters given by Von Heijne [134t. The location of acidic $(\downarrow)$ and basic $(\uparrow)$ residues is indicated by arrows. ments exist, this would indicate that the $\mathrm{C}$-terminal end would be located on the periplasmic side. ondary structures in the $F_{0}$ subunit $b$ from $E$. colli. $\alpha$-helical regions (le) and $\beta$-turns (T) were consistently predicted by fou
J., Brunner, J. and Jørgensen, B.B. (1983), unpublished data).

Labelling with the freely mobile carbene-gener ating probe [ ${ }^{125}$ I]TID started very closely to the $\mathrm{N}$-terminus at Leu- 3 and ceased at Trp-26. With a nitrene-generating probe fixed to the pola headgroups of a phospholipid ('shallow probe'. Fig. 14), residues Ast-2 as well as Cys-2 as Cys-21 and Trp-26 were modified. Thus, the entire N-terminus up to Trp- 26 is embedded in the membrane and the boundaries are defined by the residues affected by the 'shallow probe'. Most likely, the N-terminal segment traverses the whole phospholipid bilaye in an $\alpha$-helical conformation $[134,135]$. But the other possibility, that the chain folds back and that Asn-2 and Trp-26 are located at the same boundary, is not excluded by the available experimental results [136]. At positions 27 and 28, two proline residues are located which will not fit into an $\alpha$-helix, and, consequently, their peptide bond can generate a rather large hydrophilic surface area. It is thus reasonable that the polypeptide chain leaves the membrane at this point.

Surprisingly, most of the $\mathrm{N}$-terminal residues were accessible to the small diffusables probe ${ }^{125}$ I]TID. This demonstrates that this segment is not buried in a core of $F_{0}$ but rather is located at the periphery. As two subunits $b$ exist in one $\mathrm{F}_{0}$, it

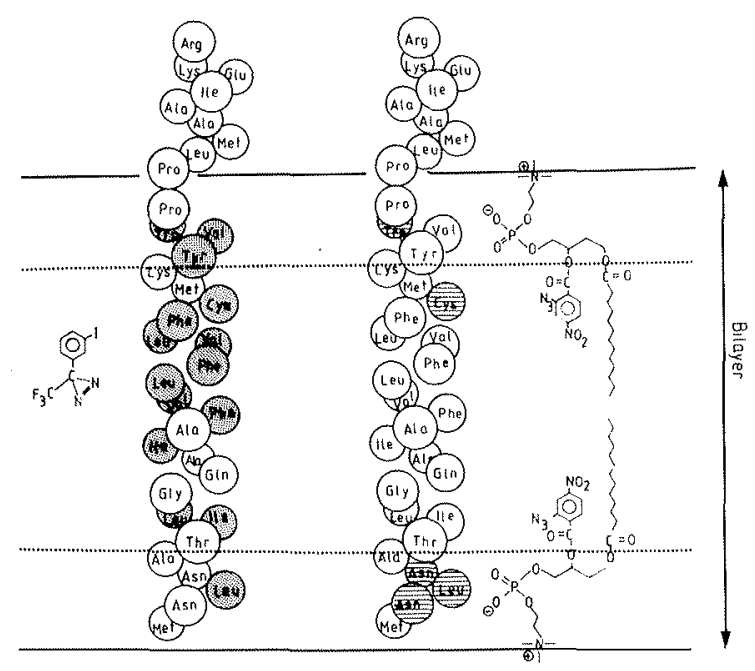

Fig. 14. A possible arrangement of the $\mathrm{N}$-terminus from subanit in the lipid bilayer. Shaded anino acid symbols indicale 'shallow probe'. remains uncertain whether the observed [ ${ }^{125}$ I]TID labelling pattern represents the same modification labelling patterns. Several of the residues not attacked by [ ${ }^{125}$ I]TID have hydrogen-bonding capacresidues might be involved in contacts with other subunits. But it could well be that a microenvironthe accumulation of [125 I]TID at these positions and thus prevents an efficient modification.

The large polar domain of subunit $b$ is clearly exposed at the cytoplasmic side of the membrane, since it can be completely degraded with proteinases [49]. The two molecules of subunit $b$ in $\mathrm{F}_{0}$ can be efficiently cross-linked (see Fig. 9). They exist, therefore, as a dimer. Most likely, the contact is formed by the large polar domain. This large polar domain binds $F_{1}$ as demonstrated in mutant membrane where the other $F_{0}$ subunits $a$ and $c$ are deleted [102]. This is not the only contact side between $F_{0}$ and $F_{1}$, since - as already mentioned - subunit $a$ also is involved in the binding of $F_{1}$ [102]. In cross-linking experiment, dimers of subunit $b$ with $\mathrm{F}_{1}$ subunits $\alpha$ and $\beta$ are observed. $\mathrm{A}$ With subunit $b$ is also indicated by the observation that in certain mutant strains subunit $b$ is protected against proteolytic degradation in vivo by the $F_{1}$ subunits $\alpha$ and/or $\beta$, even in the absence of the subunits $\gamma, \delta$, and $\epsilon$ [49]. Interestingly enough, the polar domain of subunit $b$ contains internal repeats [29]. Residues 53-82 are clearly homologous with residues 85-105. Furthermore, a shorter reresidues 101-113 [29]. Thus it can be visualize that the subunit $b$ dimer contains four roughly equivalent domains which might interact with the multiple copies of subunits $\alpha$ and $\beta$ present in $F_{1}$ Point mutations in subunit $b$ (see Table III) $[105,112]$ result in a weakened binding of $F_{1}$. Unfortunately, the mutated amino acid residue has not yet been identified.

\section{VIC. Subunit}

The polarity profile of the amino acid sequence of the $E$. coli subunit $c$ (see Fig. 15), ie two hydrophobic segments interrupted by a hydroof each of the subunits or the sum of two different ity (Asn-2, Thr-6, Gln-10, Lys-23, Tyr-24). These peat is found, residues $84-98$ are homologous to

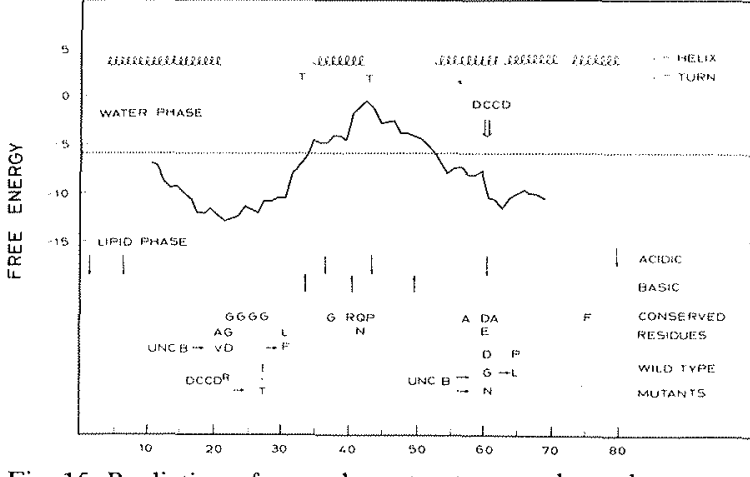

Fig. 15. Prediction of secondary structures and membrane-permeating segments in $F_{0}$ subunit $c$ of $E$. coli. $\alpha$-helical segments $(2)$ and $\beta$-turns ( $T$ were consistently calculated applying four different prediction methods [77-80]. The free-energy gain during a transition from a random coll in water to an $\alpha$-helix in positions using the parameters given by Von Heijne [134].

philic segment, is found to be conserved in the homologous subunits from other bacteria, as well as from mitochondria and chloroplasts. This clustering of hydrophobic and hydrophilic residues immediately suggested that the protein might traverse the membrane twice in a hairpin-like structure. Indeed, labelling experiments with ${ }^{125}$ I]TID indicate both hydrophobic segments being located in the lipid bilayer. Especially intriguing is the location of the acidic residue Asp-61 in the membrane, as demonstrated by its reactivity towards only hydrophobic carbodiimides. Remarkably, an acidic group is not tolerated in the N-terminal segment at position 23 of the $E$. coli protein, as seen with subunit $c$ from a mutant unc the membrane. Only distinct residues of the subunit $c$ are accessible to the label ${ }^{125}$ I]TID in functional $F_{0}$. In certain special cases, the nonlabelling by TID might be explained by a low reactivity of the side chain (e.g., alanine; see Hoppe, J., Brunner, J. and Jorgensen, B.B. (1983), unpublished data) or by the instability of the reaction product (e.g., aspartyl ester). But certainly, in most cases residues are not labelled, since they are buried in the interior of the quarternary structure of $\mathrm{F}_{0}$. It may be relevant in this connection that a mutant proteolipid from $E$. coli, which is unable to assemble (see Table IV), has an amino acid substitut E 429, (see Table IV) which is not integrated into

7


of Ala- 21 by valine in a segment not accessible to TID.

Possibly, the small side-chain of the alanine at position 21 is part of a contact site in the tertiary structure of the proteolipid or the quarterly structure of $\mathrm{F}_{0}$, and, therefore, no larger side-chain is tolerated at this position. The pattern of [ ${ }^{125}$ I]TIDlabelled residues cannot be unambiguously interpreted at the moment, since the labelling of individual subunit $c$ molecules in the $\mathrm{F}_{0}$ might be different It is consicuous, however, that at the different. is is con $N$-terminal segme cont the labelled residues would mark one side of a continuous $\alpha$-helix. Also in the C-terminal part the labelled residues could be located on $\alpha$-helical segments.

It has been discussed previously that certain residues of the proteolipid altered in oligomycinresistant mutants from yeast and Neurospora are accessible from the lipid phase. It was therefore interesting to examine when these residues cors in the $E$ coli proteolipid. Three amino acids altered in the proteolipid from inhibitor-resistant mutants occur at positions coinciding or juxtaposed to TID-labelled residues from the $E$. coli proteolipid (Fig. 16). In two instances, however, the mutated residue is located two positions apart.

Unfortunately, [ ${ }^{125}$ I]TID labelling experiments
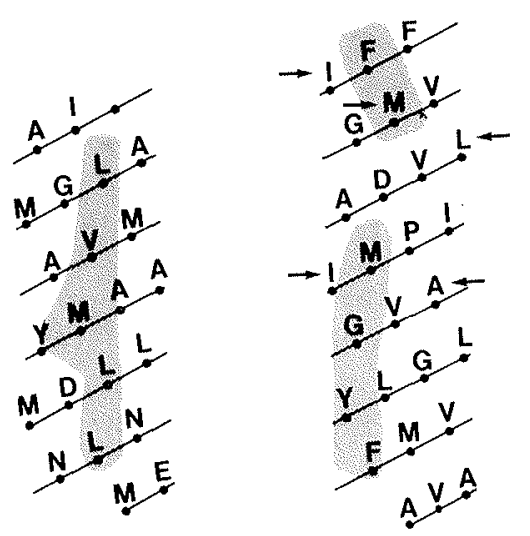

Fig. 16. Areas of subunit c from the E. coli ATP synthase which are exposed at the lipid phase and positions of amino acid exchanges in oligomycin-resistant mutants from yeast and $N$. crassa. A planar representation of the two putative $\alpha$-helices at the $\mathrm{N}$-terminus and the $\mathrm{C}$-terminus is shown. Shaded area indicate residues possibly in contact with lipids as revealed by labelling with ${ }^{212}$ i]ThD. Arrows indicate positions where amino acid substitution leading to oligomycin resistance was found. have not been performed with the mitochondrial proteolipids. Thus, it is uncertain whether corresponding positions in the bacterial or mitochondrial proteolipids are equally accessible from the lipid phase. It has to be stated, however, that in an $\alpha$-helical confirmation, some mutated residue would point in opposite directions.

The various positions determining the oligomycin resistance all are located in the vicinity of the DCCD-reactive acidic residue in the $C$-termina DCCD-reactive acidic residue in the C-terninal

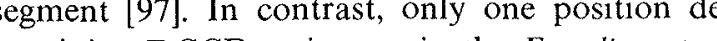
ermining DCCD resistance in the E. coli proteolipid, i.e., Mle-28, was found in the N-termina segment [115]. In a hairpin-like structure of the proteolipid, this residue would be located in proximity to the carbodiimide reactive aspartic residue. It is likely that Ile-28 is involved in noncovalent binding of e.g., the cyclohexyl moiety of DCCD. Surprisingly enough, Ile-28 is not accessTID and DCCDences in serical factors between TID and DCCD are di ficult to evaluate, but are not a likely explanation for the different accessibility of Ile-28 for both compounds. It is a distinct possibility that either DCCD is bound via an 'induced fit' or that DCCD binds only to a certain conformation of the $F_{0}$ occurring with a low probability.

The experimental data discussed above are relevant with respect to the structural properties of the proteolipid. In order to elucidate the mechanism of the proton conduction, it is also important to identify functional residues - i.e., residues directly involved in proton conductance. It has been suggested that Asp-61 in the E. coli proteolipid is such a functional residue. (All structural evidence indicates this residue being located in the interior of the membran DCCD abolishes pre DCCD abolishes proton conductance. The importance of this residue was further indicated by the observation that this acidic residue is strictly conserved in the proteolipids from mitochondria, bacterial and chloroplasts. Futhermore, proton conduction is lost if this residue is genetically altered.

Some observations, however, are difficult to reconcile with a purely functional role of this acidic residue. This residue is accessible from the lipid phase and is therefore most likely not located in the interior of a pore. A minimal genetic altera- tion of this residue (Asp $\rightarrow$ Asn) leads to impaired binding of $F_{1}$ (see chapter IVC-1) and the $F_{0}$ subunit $b$. Apparently, large conformational changes are induced in the whole $F_{0}$ by this mutation.

VID. Models for proton conductance

All available evidence points to the proteolipid Abunit as the protonophoric entity of the $F_{0}$. argue against a direct participation of subunits $a$ and $b$ in transmembrane protontranslocation. The large hydrophilic part of subunit $b$ might be involved in the coupling between the proton trans brane and ATP synthesis/hydrolysis on the $F_{1}$, but it is unlikely, that the short uncharged $\mathrm{NH}_{2}$ terminal segment, which has only loose contact with the other subunits, provides residues participating in the subunit a contains the proton pathway, then only the few conserved residues may be considered which are clustered in a short segment. For subunit $c$ Schindler and Nelson [133] provided convincing evidence that the isolated protein functions as a protonophore, when reconstituted in black lipid membranes. These in vitro experiments seem to contradict results obtained with mutant membranes from $E$. coli, which contain only the $\mathrm{F}_{0}$-subunit $c$ and which are unable to conduct protons [102]. This discrepancy might be resolved by the observation of Schindler and Nelson th the active proton channel formed in black lipid membranes is at least a dimer and probably a higher oligomer of the subunit $c$. In vivo this functional oligomer might be stabilized by the $F_{0}$ subunit $a$ and/or $b$ as originally proposed by Nelson and Schatz [92].

Therefore, at present any discussion on the mechanism of proton conductance will concentrate on a subunit $c$ oligomer. However, based on the presently available structural data, the mechanism of proton conductance is completely obscure. The membrane spanning segments subunit $c$ contain only a few polar residues and only one charged residue - the invariant DCCDreactive aspart ficult to comsic acid. Therefore, in appears difficult to construct a network of hydrogen bond across the membrane from amino acid side-chain
137]. An alternative would be that the oligomer of subunit $c$ binds water either by the anino a side-chains or by the polar groups of peptide bonds. In many instances, buried water cluster were found in the interior of globular proteins. For example, in studies with chymotrypsin, it was discussed that each region associated with buried charged groups contained an extensive hydrogenbonded network including several buried water molecules [138]. Recent X-ray studies on lamethicin, which forms an oligomeric voltagegated ion channel, shed light on the possible in volvement of bound water molecules in cation ransport [139]. The alamethicin monomer forms an helix which has a bend in the middle due to the accurrence of a proline residue. This proline-induced bend results in two free carbonyls and one free amide group of the peptide backbone, thus providing a hydrophilic surface (Fig. 17). It was visualized that this area, together with a buried glutamine residue, is able to bind a large number of water molecules. A corresponding water-binding structural element might be present in subunit $c$. In the middle of the $\mathrm{C}$-terminal hydrophobic segment a proline residue is found in all bacterial proteins. In the mitochondrial and chloroplast proteolipids generally a helix-breaking residue (threonine, glycine) exists at the corresponding position. This bend is located four residues apart from the membrane buried acidic residue Asp-61.

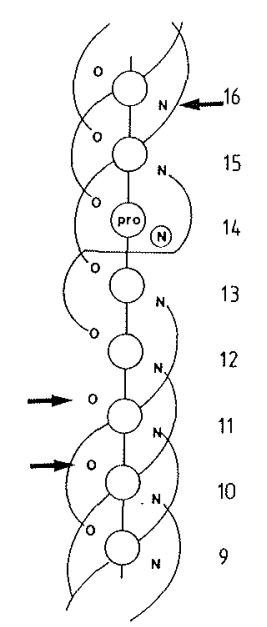

Fig. 17. Backbone hydrogen bonding in alamethicin around proline-14 [139]. The arrows indicate free carbonyl or amide groups of peptide bonds. 
However, the participation of this acidic residue in the formation of a water cluster inside a pore is difficult to reconcile with its reactivity to DCCD.

The central question concerning all studies directed to structure and function is whether $F_{0}$ can exist in different conformations. In the $F_{1}$-ATPase, extensive conformational changes occur upon energization of the membrane and during ATP hydrolysis or synthesis [4]. It could well be that conformational changes in $\mathrm{F}_{1}$ are accompanied or even coupled to conformational changes in $F_{0}$. Papa and co-workers [140] provided experimental evidence for two different conformation states of the proton conductor in dependency of the applied $\Delta \mu_{\mathrm{H}^{+}}$in beef-heart mitochondria. Also, the inhibitory action of oligomycin can be readily explained if this macrocyclic compound induces or stabilizes one structural state. The same inhibitory mechanism may apply for DCCD. Pleiotropic effects of amino acid substitutions in subunit $c$ (see subsection IVC) might be caused by allosteric interaction. A mechanism of proton translocation by a reorientating basic or acidic group has been developed by Boyer [141]. Obviously, such a mechanism requires conformational changes in the $F_{0}$. It should be possible with the techniques now available to define these putative conformational states more precisely and to correlate such states with the function of the enzyme.

\section{Perspectives}

ATP synthase and the proton conducting component $\mathrm{F}_{0}$ from the bacterial PS-3 [48] and $E$. coli [9-11] have been purified only a few years ago. Since then, our understanding of structure and function of $F_{0}$ has rapidly advanced, as detailed in function of $F_{0}$ has rapidly advanced, as detailed in
this review. For the studies on $F_{0}$, the experimental this review. For the studies on $F_{0}$, the experimental possibilities now available have not been fully exploited. The availability of isolated subunil $\mathrm{F}_{0^{-}}$ by site-directed mutagenesis. Hopefully, mutants will be obtained which exhibit specific defects, e.g., only in proton conductance or only in $F_{1}$ e.g., only in proton conductance or only in $F_{1-}^{-}$
binding. Furthermore, the assembly of $F_{0}$ might now be studied, and an in vivo reconstitution of $F_{0}$ now be studied, and an in vivo reconstitution of $\mathrm{F}_{0}$
seems to be feasible after recombination of the seems to be feasible after recombination of the
isolated subunit genes with appropriate expression vectors.
The topology of all three $\mathrm{F}_{0}$-subunits might be elucidated in more detail by means of antibodies, directed against defined polar segments of the polypeptide chains. The amino acid sequences will furthermore give hint for possible chemical modification studies directed towards identification of functional residues or towards the accessibility of certain segments.

Conformational changes might be defined by membrane permeating photoreactive probes an by the covalent attachment of reporter groups, i.e. spin labels or fluorescence label. Finally, it might be possible to obtain $\mathbf{F}_{0}$-crystals sufficient for high resolution X-ray analysis. Hopefully, the result obtained by proteinchemical, physiochemical and genetic methods then can be integrated into a consistent picture

\section{References}

1 Downie, J.A., Gibson, F. 3nd Cox, G.B. (1979) Annu.

Gibson, F. (1982) Proc. R. Soc. Lond. B 215, 1-18

Reference deleted

4 Senior, A.E., and Wise, J.G. (1983) J. Membrane Biol. 73, $105-124$

197ngane, R.H. (1980) Annu. Rev. Biochem. 49, 1079-1113

6 Sebald, W. and Hoppe, J. (1981) Current Topics in Bioenergetics (Sanadi, D.R., ed.), Vol. 12, pp. 2-59, Academi Press, New York

7 Foster, D.L. and Fillingame, R.H. (1979) J. Biol. Chem 254, 8230-8236

Friedl, P., Friedl, C. and Schairer, H.U. (1979) Eur. J. Biochem. 100, 175-180

Bion, R.S., Foster, D.L. and Fillingame, R.H. (1980) J.

10 Friedl, P. and Schairer, H.U. (1981) FEBS Lett. 128 261-264

11 Schneider, E.A. and Altendorf, K. (1982) Eur. J. Biochem. $126,149-153$

12 Downie, J.A., Cox, G.B., Langman, L., Ash, G., Becher, M. and Gibson, F. (1981) J. Bacteriol. 145, 200-210

Hansen, F.G., Nielsen, J., Riise, E. and Von Meyenburs K. (1981) Mol. Gen. Genet. 183, 463-472

Gay, N.J. and Walker, J.E. (1981) Nucleic Acids Res. 9 2987-2194

15 Gay, J.N. and Walker, J.E. (1981) Nucleic Acids Res. 9

16 Saraste, M., Gay, N.J., Eberle, A., Runswick, M.J. and Nielsen J. (1981) Nucleic Acids Res. 9, 5287-5296 Meyenburg L. (1981) Mel Gen Gen M. 184, 33 39 Vo 8 Kanazawa, H., Mabuchi, K., Kayano, T., Tamura, F. $219-225$
19 Mabuchi, K., Kanazawa, H., Kayano, T. and Futai, M. (1981) Biochem. Biophys. Res. Commun. 102, 179

0 Kanazawa, H., Kayano, T., Mabuchi, K. and Futai, M. (1981) Biochem. Biophys. Res. Commun. 102, 604-612

21 Kanazawa, H., Mabuchi, K., Kayano, F., Noumi, T. Sekiya, T. and Futai, M. (1981) Biochem. Biophys. Res. Commun. 103, 613-620

22 Kanazawa, H., Mabuchi, K. and Futai, M. (1982) Biochem. Biophys. Res. Commun. 107, 568-575

23 Kanazawa, H., Kayano, T., Kiyasu, T. and Futai, M. (1982) Biochem. Biophys. Res, Connun. 105, 1257-1264 24 Foster, D.L. and $2009-2015$

5 Von Meyenburg, K., Jфrgensen, B.B., Nielsen, J., Hansen, F. and Michelsen, O (1982) Tokai J. Exp. Clin. Med, in the press

26 Sebald, W., Graf, T. and Lukins, H.B. (1979) Eur. J. Biochem. 93, 587-599

27 Sigrist-Nelsen, K., Sigrist, H. and Azzi, A. (1978) Eur. J. Biochem. 92, 9-14

28 Hoppe, J., Brunner, J., Friedl, P., Lincoln, D., Von Meyenburg, K., Michelsen, O. and Sebald, W. (1982) $2 \mathrm{n}$ European Bioenergetic Conference, Short report, pp. 85-86 29 Walker, J.E., Saraste, M. and Gay, N.J. (1982) Nature 298

Unwin, P.N.T. and Henderson, R. (1975) J. Mol. Biol. 94

erson, R. and Unwin, P.N.T. (1975) Nature 257, 28-32

32 Fuller, S.D., Capaldi, R.A. and Henderson, R. (1979) J. Mol. Biol. 134, 305-327

33 Deatherage, J.F., Henderson, R. and Capaldi, R.A. (1982) J. Mol. Biol. 158, 487-499

34 Deatherage, J.F., Henderson, R. and Capaldi, R.A. (1982) J. Mol. Biol. 158, 501-514

35 Michel, H. and Oesterhelt, D. (1980) Proc. Natl, Acad. Sci U.S.A. $77,1283-1285$

36 Michel, H. (1982) J. Mol. Biol. 158, 567-572

Michel, H. (1982) EMBO J. 1, 1267-127

Etemadi, A.H. (1980) Biochim. Biophys. Acta 604, 347-42 Singer, S.J. (1974) Annu. Rev. Biochem. 43, 805-833

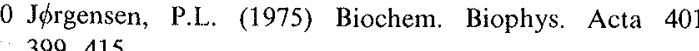

683, 279-301

O2 Ovchinnikov Y A. (1979) Eur J Biochem. 94, 321-336 43 Ovchinnikov, Y.A. (1981) in Chemiosmotic Proton Ci cuits in Biological Membranes (Skulachev, V.P. and Hinkle, P.C., eds.), pp. 311-320, Addison-Wesley Publishing Company

Ovchinnikow, Y.A., Abdulaev, N.G. and Modyanov, N.N. (1982) Annu. Rev. Biophys. Bioenerg. 11, 445-463

Khorana, H.G., Gerber, G.E., Herlihy, W.C., Gray, C.P. Anderegg, R.J., Nihei, K. and Biemann, K. (1979) Proc En Acad. Sci. U.S.A. 17, 5046-5050

Engelman, D.M., Henderson, R., McLachlan, A.D. an Di. U.A. 77, 2023-2027
47 Engelman, D.M. and Zaccai, G. (1980) Proc. Nat1. Acad. Sci. U.S.A. 77, 5894-5898

48 Sone, N., Yoshida, M. Hirat, H, and Kagawa, Y, (1978) Proc. Natl. Acad. Sci. U.S.A. 75, 4219-4223

Hoppe, J., Friedl, P., Schairer, H.U. Meyenburg, K. and Jørgensen, B.B. (1983) EMBO J. 2,

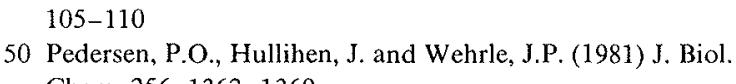
Chem. 256, 1362-1369

51 Loo, T.W. and Bragg, P.D. (1982) Biochem. Biophys. Res.

2 Hopp, T.P. and Woods, K.R. (1981) Proc. Natl. Acad. Sci.

$46,69-114$

Biochem. 48, 293-325

S6. Staros, J.V. (1980) Trends Biochem. Sci. 5, 320-322

57 Bercovici, T. and Gitler, C. (1978) Biochemistry 17,

58 Wells, E. and Findlay, J.B. (1979) Biochem. J. 179, 265-272 99 Bayley, H. and Knowles, J.R. (1978) Biochemistry 17, 2420-2423

60 Brunner, J. and Semenza, G. (1981) Biochemistry 20,

1 Cerletti, N. and Schatz, G. (1979) J. Biol. Chem. 254,

2 Bayley, $\mathrm{H}$

2414-2419

63 Bramhall, J.S., Shiflett,

Biochem. J. 177, 765-768.A. and Wisnieski, B.J. (1979)

$64 \mathrm{Hu}$, V.W. and Wisnieski,

U.S.A. 76, 54-60-54-64 757-763

66 Chakrabarti, P. and Khorana, H.G. (1975) Biochemistry
14, 5021-5033 Gupta, C.M., Radhagrishnan, R. and Khorana, H.G. (1977) roc. Natl. Acad. Sci. U.S.A. 74, 4315-4319

68 Brunner, J. and Richards, F.M. (1980) J. Biol. Chem. 255,

Chon, R., Steffens, G.C.M. and Buse, G. (1982) J. Biol.

Ross, A.H., Radhakrishnan, R., Robson, R.J. and Khorana,

and Friedl, P. (1983) J. Biol. Chem. 258, 2882-2885

72 Hoppe, J., Friedl, P. and J $\phi$ rgensen, B.B. (1983) FEBS Lett. 160, 239-242

73 Nielsen, P.E. and Buchardt, O. (1982) Photobiology 35, $317-323$

74 Sebald, W., Friedl, P., Schairer, H.U. and Hoppe, J. (1982) Annu. N.Y. Acad. Sci. U.S.A. 402, 28-44

75 Hoppe, J. and Sebald, W. (1982) in Chemistry of Peptides and Proteins, Vol. 1 (Voelter, W., Wünsch, E., OvchinniGruyter \& Co., Berlin 
76 Mao, D., Wachter, E. and Wallace, B.A. (1982) Biochemistry $21,4960-4968$

D. (1978) Adv. Enzymol. Relat. Areas Mol. Biol. 47, 45-148

8 Nagano, K. (1974) J. Mol. Biol. 84, 337-372

79 Robson, B. and Suzuki, E. (1976) J. Mol. Biol. 107, 327-356 80 Maxfield, F.R. (1976) Biochemistry 15, 5138-5153

81 Macino, G. and Tzagoloff, A. (1980) Cell 20, 507-517

2 Anderson, S., Bankier, A.T., Barrel, B.G., de Bruijn, M.H.L., Coulsen, A.R., Dronin, J., Eperon, I.C., Nierlich, D.P., Roe, B.A., Sanger, F., Schreier, P.H., Smitz, A.J.H., Staden, R. and Young, J.G. (1982) Nature (London) 290

83 Bibb, M.J., van Etten, R.A., Wright, C.T., Walberg, M.W And Clayton, D.A. (1981) CH 26,

J.C. Sun, S, F. and Young IG. (1982) J. M.R., Eperon, 683-717

85 Macino, G. and Tzagoloff, A. (1979) J. Biol. Chem. 254, $4617-4623$

A Perz, A. and Sebald, W. (1982) EMBO J. 1, 565-571

87 Herrmann, R.G., Seyer, P., Schedel, R., Gordon, K., Bisanz, C., Winter, P., Hildebrandt, J.W., Wlaschek, M., Alt J., Driesel, A.J. and Sears, B.B. (1980) in Biological Chemistry of Organelle Formation (Bucher, Th., Sebald, W. and Weiss, H., eds.), pp. 97-112, Springer-Verlag, Berlin

88 Tzagoloff, A., Macino, G. and Sebald, W. (1979) Ann
Rev. Biochem. 48, 419-441 Sebald, W. (1977) Biochim Biophys Act 463, 1-27

90 Howe, C.J., Auffret, A.D., Doherty, A., Bowman, C.M. Dyer T A Gray, J.C. (1982) Proc. Natl Acad Sci U S A 79, 6903-6907

91 Alt, J., Winter, P., Sebald, W., Moser, J.G., Schedel, R. Westhoff, P. and Herrmann, R.H. (1983) Curr. Genet. ? $129-138$

92 Nelson, N., Nelson, H., and Schatz, G. (1980) Proc. Natl. Acad. Sci. U.S.A. 77, 1361-1364

93 Tzagoloff, A., Akai, A., Needleman, R.B. and Zulch. G. (1975) J. Biol. Chem. 250, 8236-8242

94 Foury, F. and Tzagoloff A. (1976) Eur J. Biochem 68,

95 Coruzzi, G., Trembath, M.K. and Tzagoloff, A. (1978) Eur. J. Biochem. 92, 279-287

6 Lancashire, W.E. and Mattoon, J.R. (1979) Mol. Gen. Genet. 176, 255-264

Rald, W., Wachter, E. and Tzagoloff, A. (1979) Eur. J. $599-607$

88 Miki, T Hirasa, S. Nagata, T and Yura, T (1978) Proc. Natl. Acad. Sci. U.S.A. 75, 5099-5103

99 Von Meyenburg, K and Hansen, F. (1980) in Mechanistic Studies of DNA Replication and Genetic Recombination ICN-UCLA Symposia on Molecular and Cellular Biology (Alberts, B. and Fox, F., eds.), Vol. 19, pp. 137-159, Academic Press, New York

100 Foster, D.L., Mosher, M.E., Futai, M. and Fillingame R.H. (1980) J. Biol. Chem. 255, 12037-1204 101 Gunsalus, R.P., Brusilow, W.S.A. and Simoni, R.D. (1982)
102 Friedl, P., Hoppe, J., Gunsalus, R.P., Michelsen, O., Von Meyenburg. K and Schairer, H.U. (1983) EMBO J.2 99-103

103 Friedl, P., Bienhaus, G., Hoppe, J. and Schairer, H.U. (1981) Proc. Natl. Acad. Sci. U.S.A. 78, 6643-6646

104 Loo, T.W. and Bragg, P.D. (1981) Biochem. Biophys. Res. Commun. 103, 52-59

105 Schairer, H.U., Friedl, P., Schmid, B.I. and Vogel, O (1976) Eur. J. Biochem. 66, 257-268

106 Downie, J.A., Senior, A.E., Gibson, F and Cox, G.B. (1976) J. Bacteriol, 137, 711-718

07 Wachter, E., Schmid, R., Deckers, G. and Altendorf, K.

108 Hoppe, J., Schairer, H.U. and Sebald, W. (1980) FEBS Lett. 109. 107-111

(1982)

110 Hoppe, J. and Sebald, W. (1982) in Chemiosmotic Proton Circuits in Biological Membrane (Skulachev, V.P. and Hinkle, P.C., eds.), pp. 449-458, Addison-Wesley

111 Jans, D.A., Fimmel, A.L., Langman, L., James, L.. Down J.A., Senior, A.E., Ash, G.R., Gibson, F. and Cox, G.B. (1983) Biochem. J. 211, 717-726

112 Nuomi, T. and Kanazawa, H. (1983) Biochem. Biophys.

3 Friedl, P., Friedl, C. and Schairer, H.U. (1980) FEBS Lett. 119, 254-256

14 Roisin, M.P., Kepes, A. (1973) Biochim. Biophys. Acta

15 Hoppe, J., Schairer, H.U. and Sebald, W. (1980) Eur. J. Blochem. 112, 17-24

(1979) in Function (Quagliariello, F Palmieri, F, Piomembrane Transport M., eds.), pp. 63-74, Elsevier/North-Holland Biomedical Pres

117 Sebald, W and Wachter, E. (1980) FEBS Lett. 122 307-311

118 Cattel, K.J., Lindop, C.R., Knight, I.G. and Beechey, R.B. (1971) Biochem. J. 125, 169-177

m. 257, 6630-6637

120 Altendorf, K. (1977) FEBS Lett. 73, 271-275

121 Sone, N., Yoshida, M., Hirata, H. and Kagawa, Y. (1979a) J. Biochem. 85, 503-509

122 Hoppe, J. and Sebald, W. (1980) Eur. J. Biochem. 107

123 Glasser, E., Norling, B. and Ernster, L. (1981) Eur. J.

24 Houstek, J., Svoboda, P., Kopecky, J., Kuzela, S. and 15 Sebald, W. Machleid, W. and Wachter, E. (1980) Proc Natl. Acad. Sci. U.S.A. 77, 785-789

126 Sigrist-Nelson, K. and Azzi, A. (1979) J. Biol. Chem. 254 4470-4474

127 Sone, N., Leba, K., and Kagawa, Y. (1979b) FEBS Let. 97, 61-64

128 Sone, N., Hamamoto, T. and Kagawa, Y. (1981) J. Bio Chem. 256, 2873-2877
29 Nelson, N., Eytan, E., Notsani, B., Sigrist, H., Sigrist-Nelson, K. and Gitler, C. (1977) Proc. Natl. Acad. Sci. U.S.A. 2375-2378

130 Criddle, R.S., Packer, L. and Shieh, P. (1977) Proc, Natl. Acad. Sci. U.S.A. 74, 4306-4310

131 Celis, 32 Sigrist-Niel

133 Schindler, H. and Nelson, N. (1982) Biochemistry 21 $5787-5794$

134 Von Heijne, G. (1981) Eur. J. Biochem. 120, 275-278 136 Dailey, H.A. and Strittmatter, P (1981) J. Biol. Chem. 256, 3951-3955

137 Naglo JF and Morowiz HJ. (1978) Proc. Nall Acod. Sci. U.S.A. $75,298-302$

38 Birktoft, J.J. and Blow, D.M. (1972) J. Mol. Biol, 68 , $187-240$

139 Fox, R.O. and Richards, F.M. (1982) Nature 300, 325-330 Kopecky, J., Guerrieri, F. and Papa, S. (1983) Eur. J. Biochem. 131, 17-24

141 Boyer, P.D. (1980) First European Bioenergetics Conference, Short Reports, pp. 133-134 